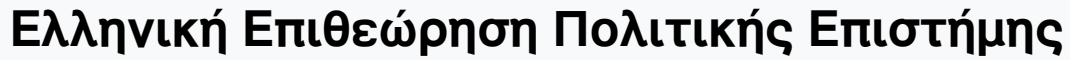

Tóp. 8, Ap. 1 (1996)

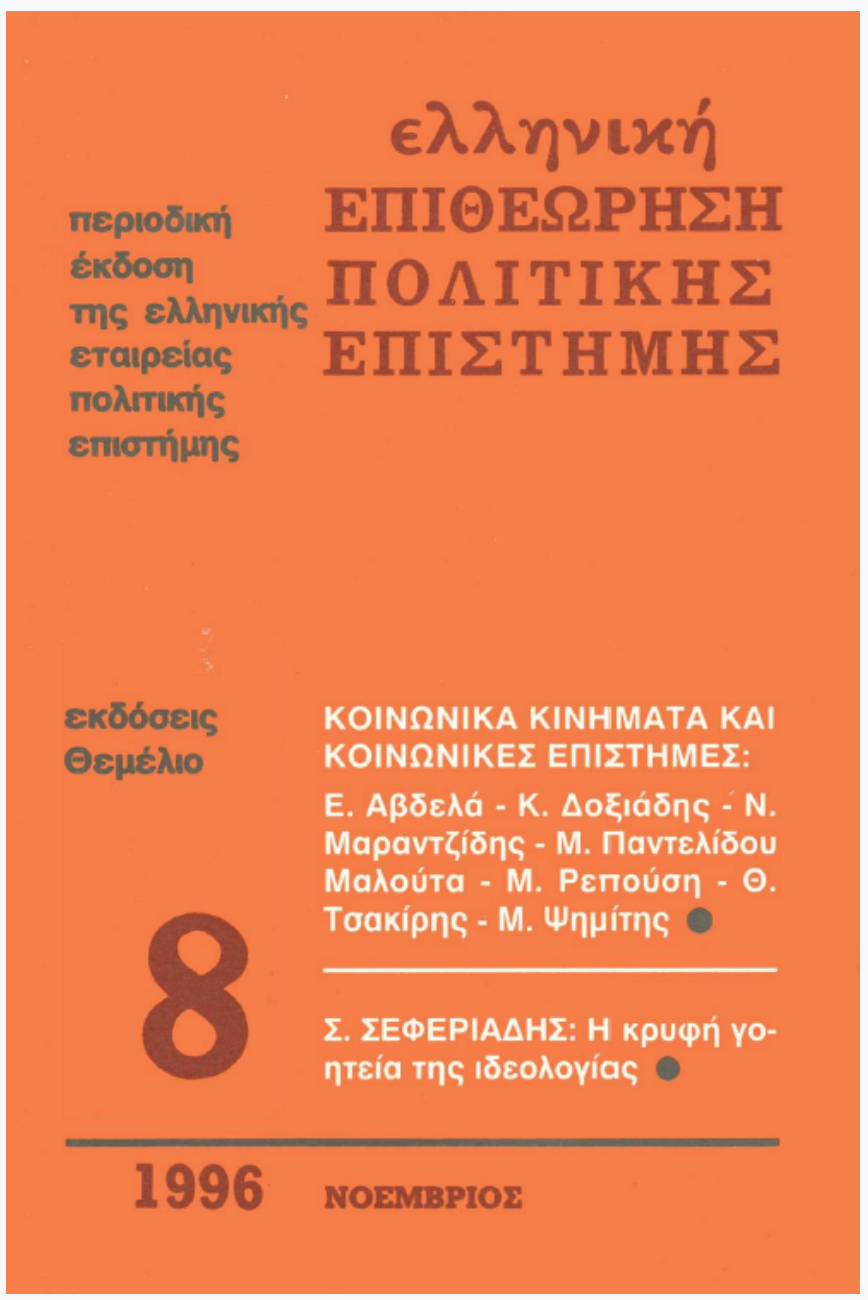

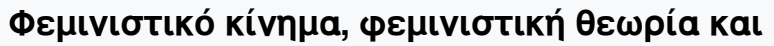 เठเótnta тou по入ítn}

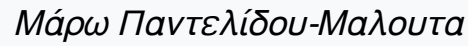

doi: $10.12681 / \mathrm{hpsa} .15243$

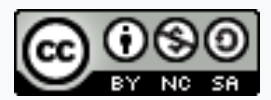

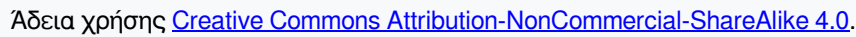

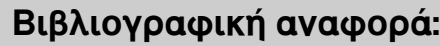

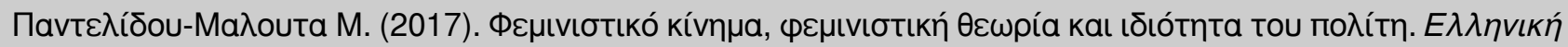

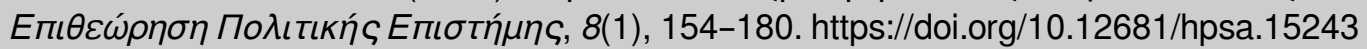




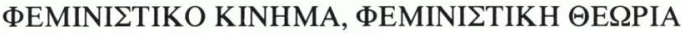 KAI IDIOTHTA TOY ПOАITH}

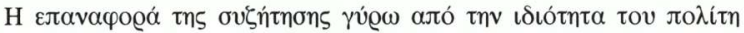

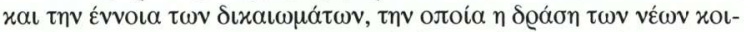

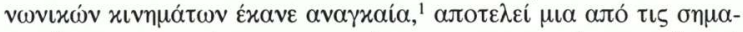

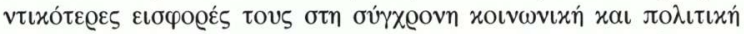

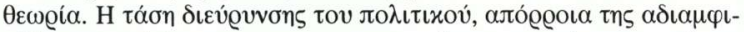

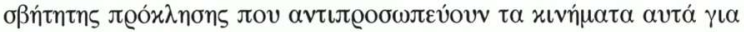

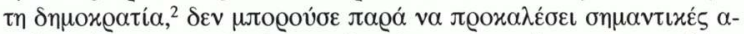

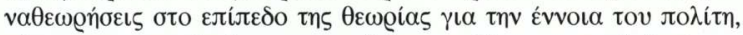

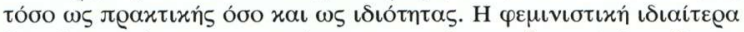

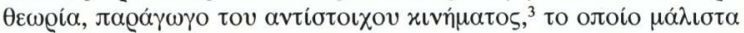

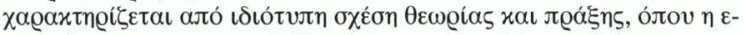

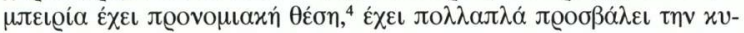

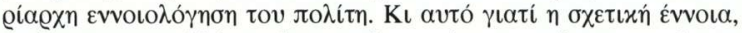

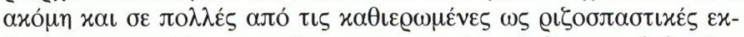

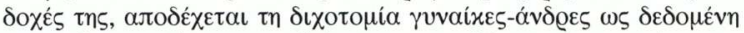

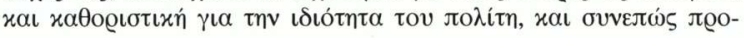

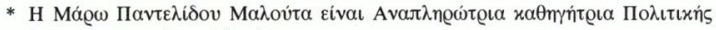
Eлเซтที

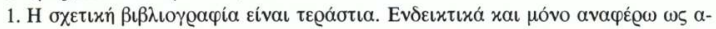

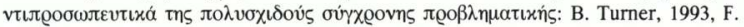

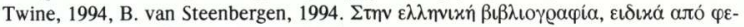

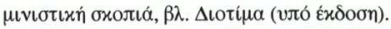

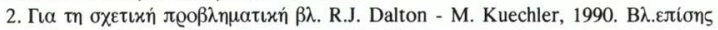

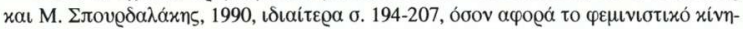

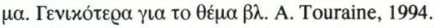

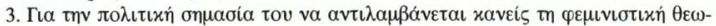

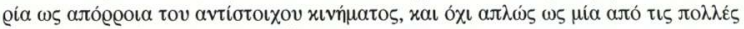

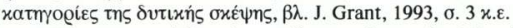

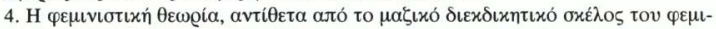

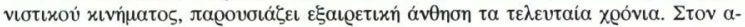

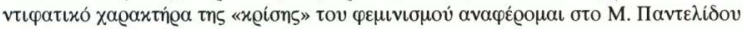

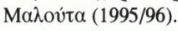




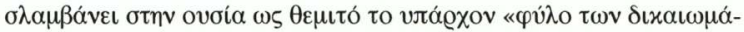
$\tau \omega v »{ }^{5} \Sigma v ́ \mu \varphi \omega v \alpha \mu \varepsilon \alpha v \tau \eta \dot{~ \tau \eta v ~ \alpha v \tau i ́ \lambda \eta \psi \eta, ~ \delta \varepsilon ~ \varphi \alpha i v \varepsilon \tau \alpha \iota ~ \pi \alpha \varrho \alpha ́ \lambda о \gamma о ~ o l ~}$

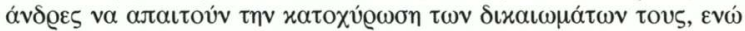

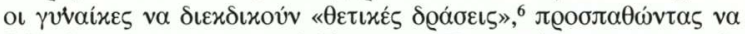

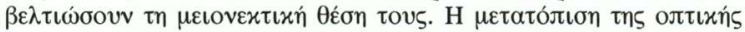

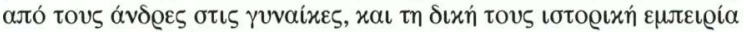

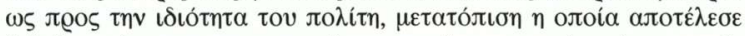

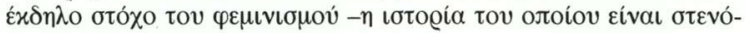

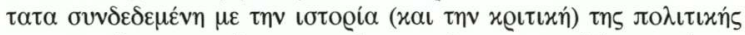

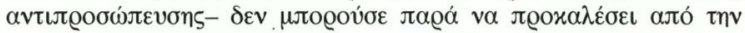

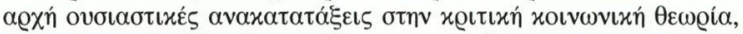

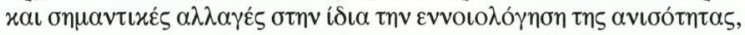

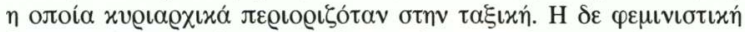

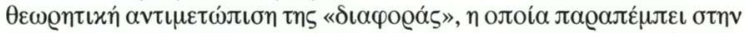

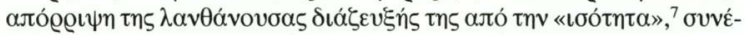

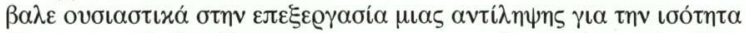

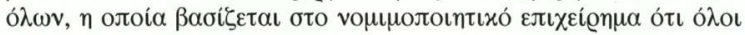

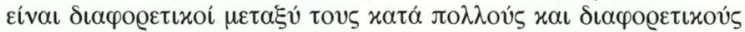

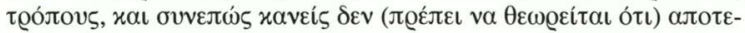

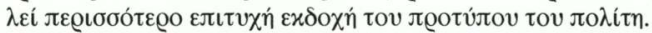

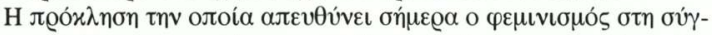

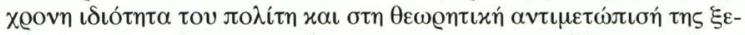

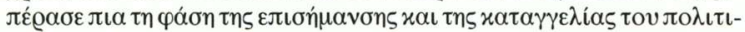

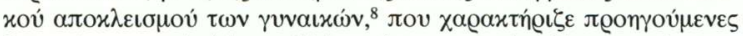

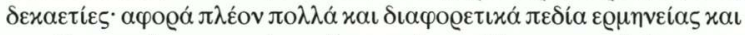

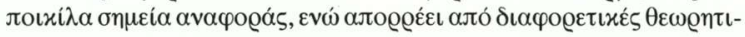

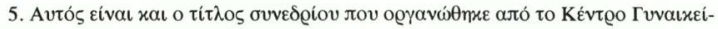

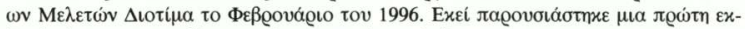

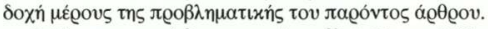

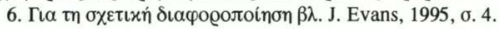

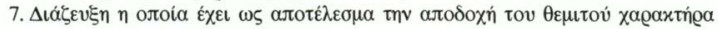

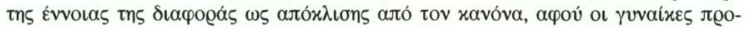

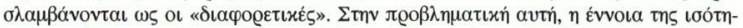

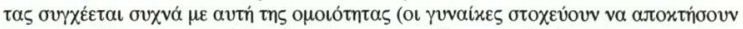

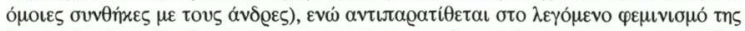

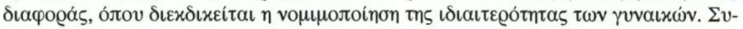

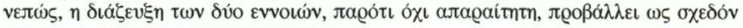

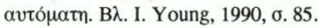

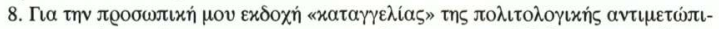

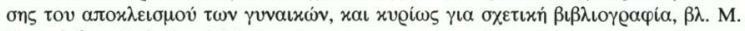

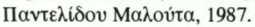




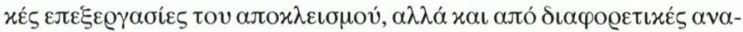

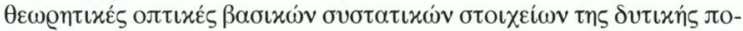

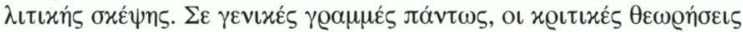

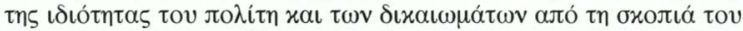

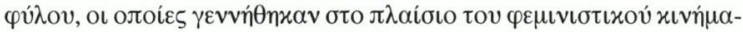

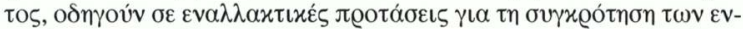

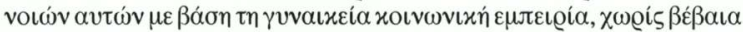

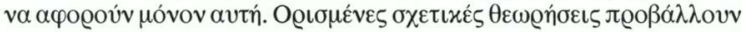

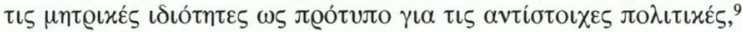

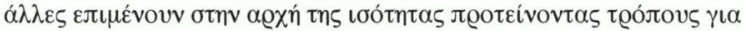

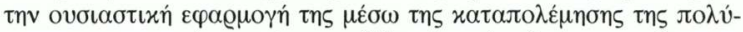

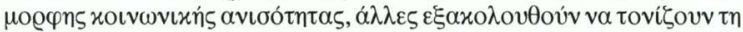

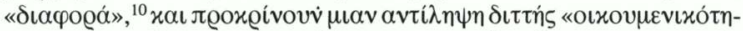

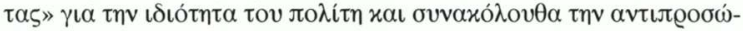

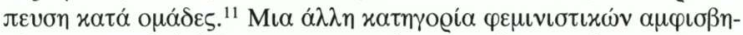

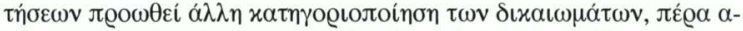

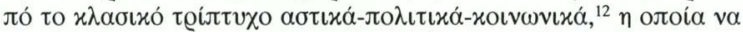

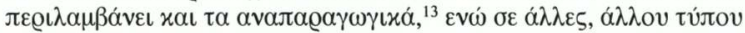

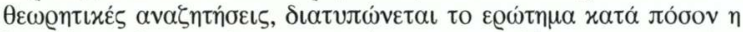

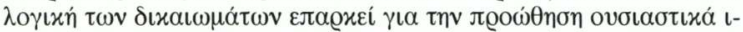

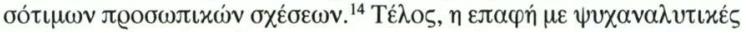

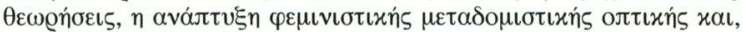

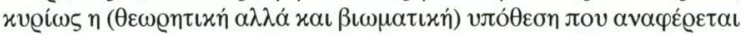

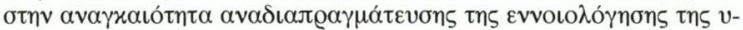

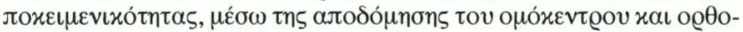

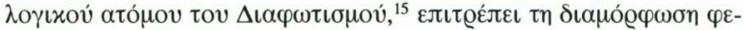

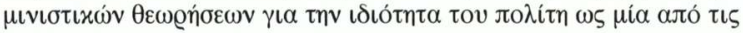

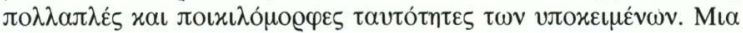

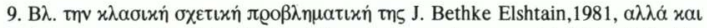

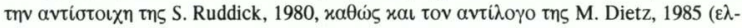
$\lambda \eta v \iota x \eta \dot{~ \mu \varepsilon \tau \alpha ́ ́ \varphi \varrho \alpha o ̛, ~ 1995) . ~}$

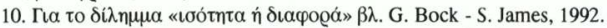

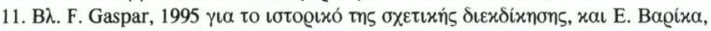

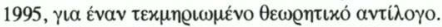

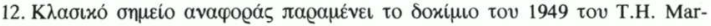
shall, 1995.

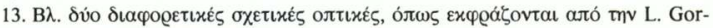
don, 1976 xa tᄁv A. Rich, 1976.

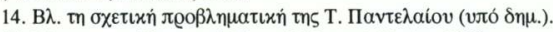

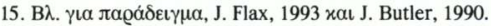




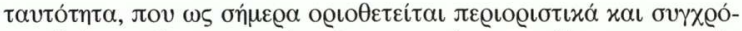

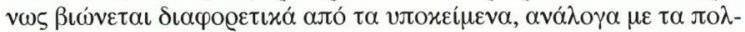

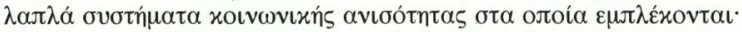

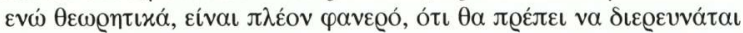

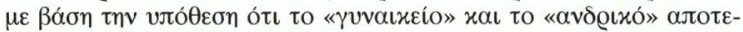

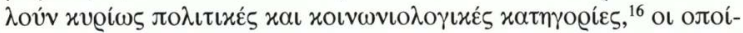

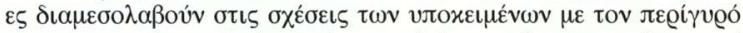

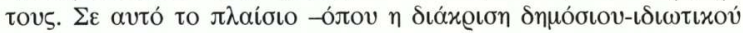

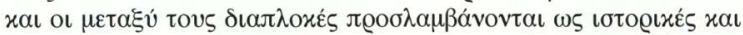

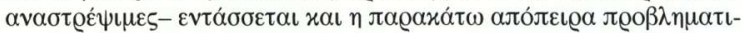

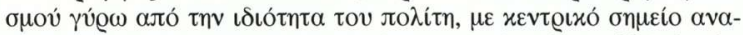

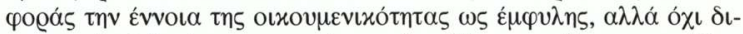

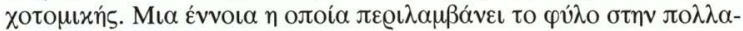

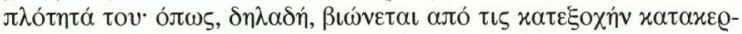

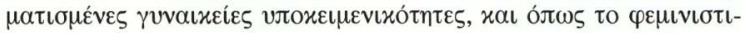

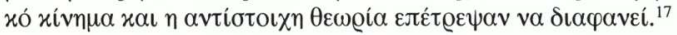

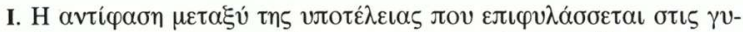

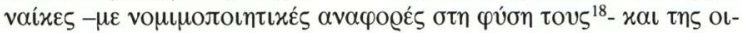

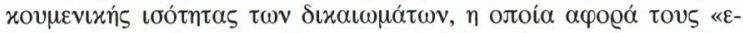

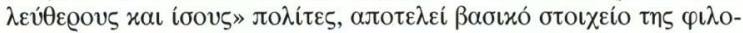

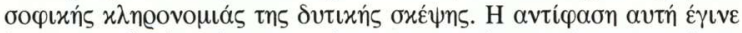

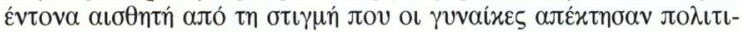

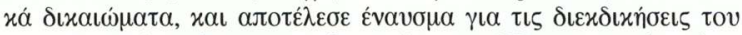

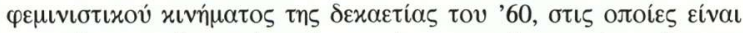

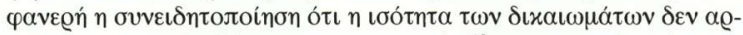

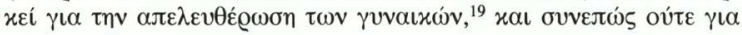

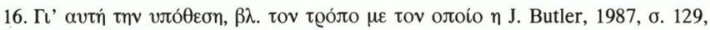

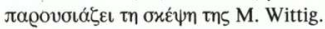

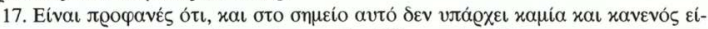

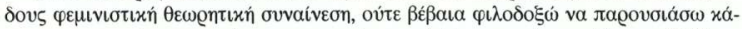

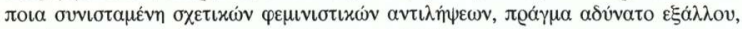

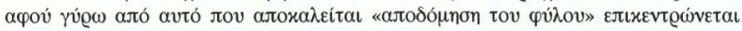

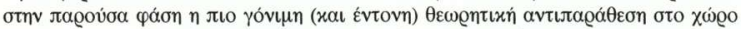

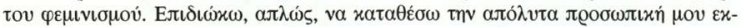

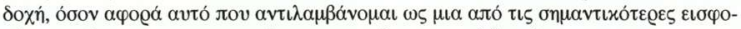

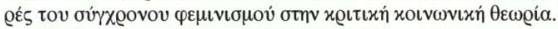

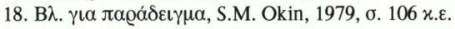

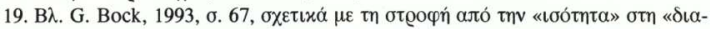

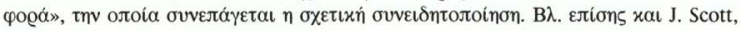

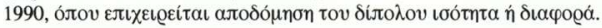




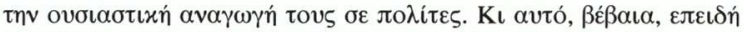

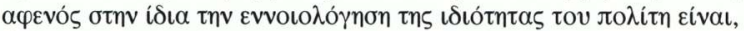

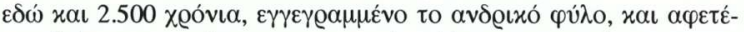

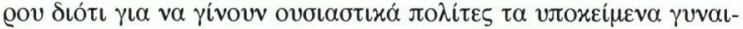

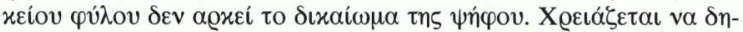

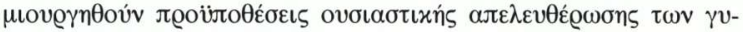

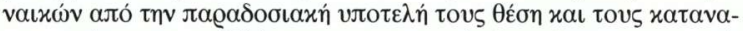

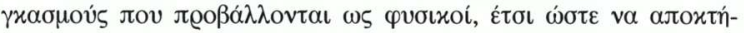

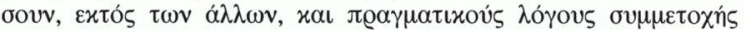

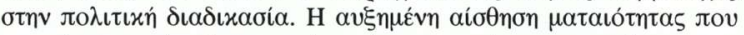

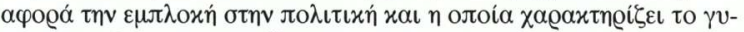

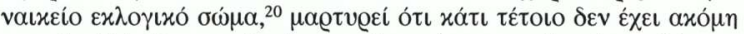

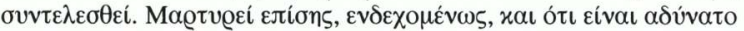

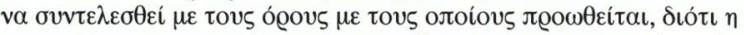

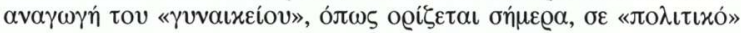

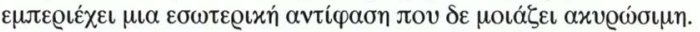

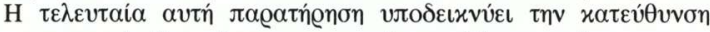

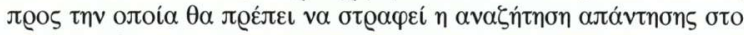

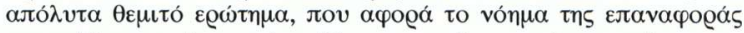

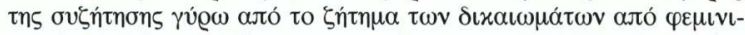

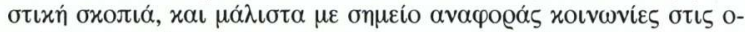

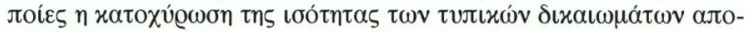

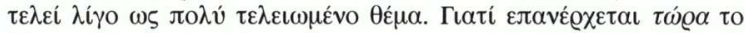

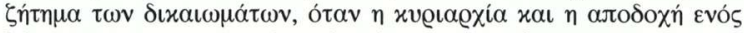

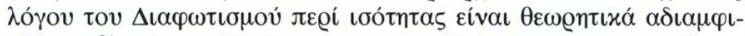

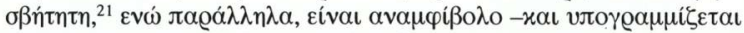

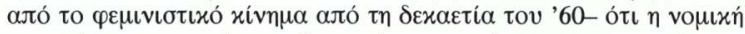

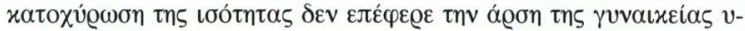

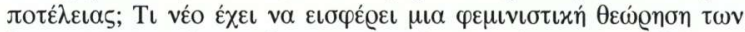

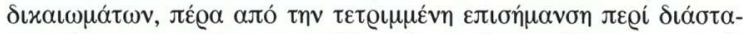

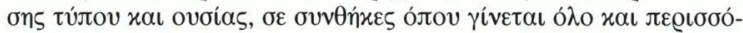

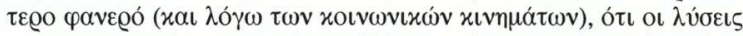

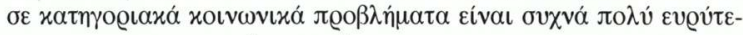

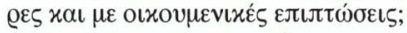

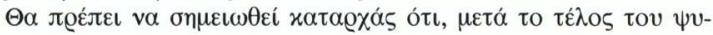

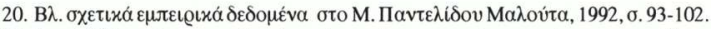

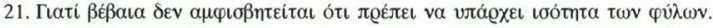

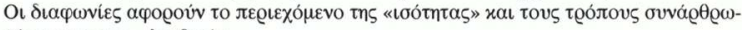
бฑं 


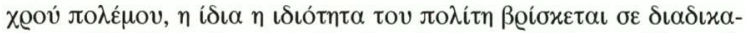

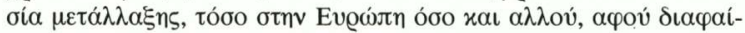

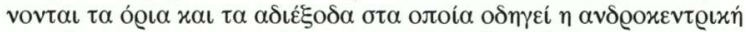

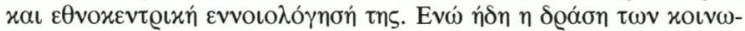

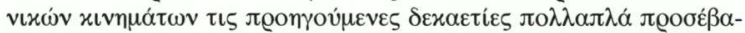

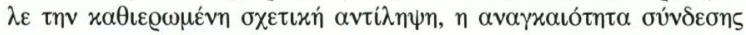

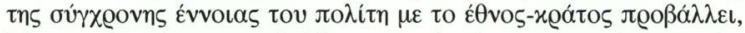

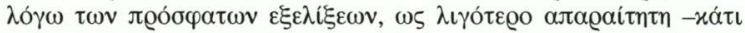

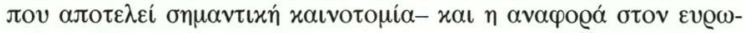

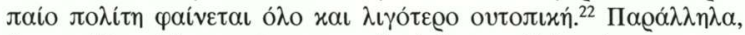

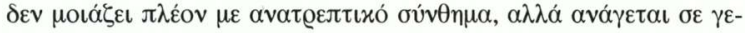

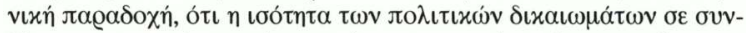

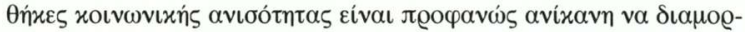

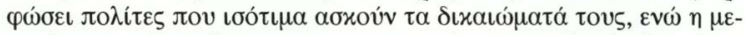

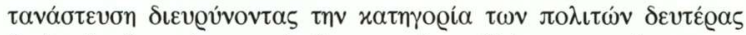

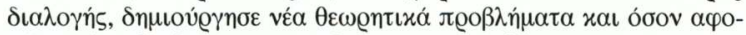

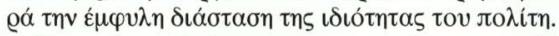

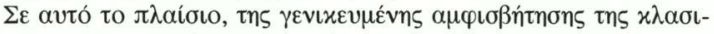

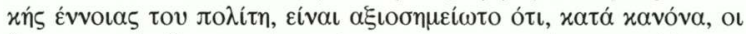

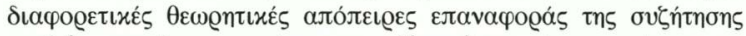

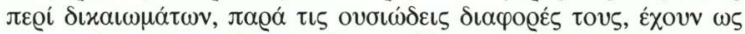

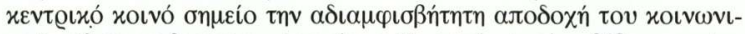

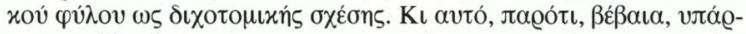

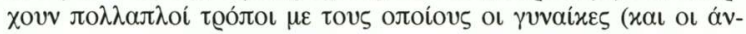

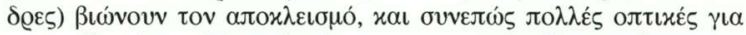

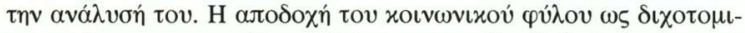

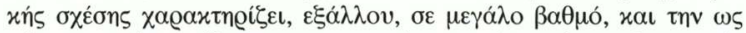

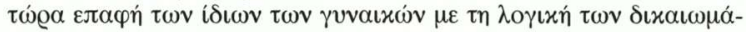

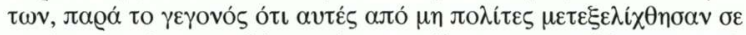

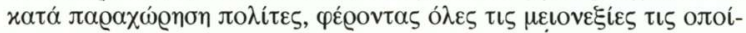

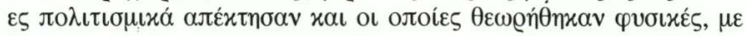

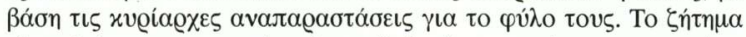

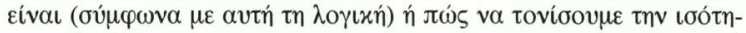

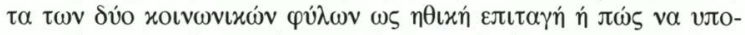

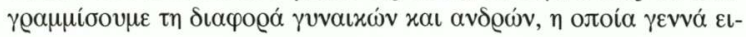

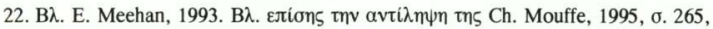

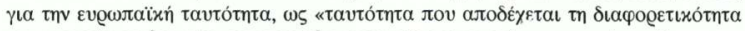

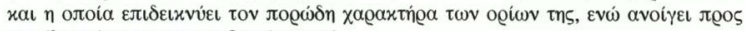

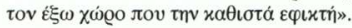




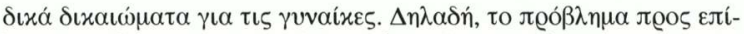

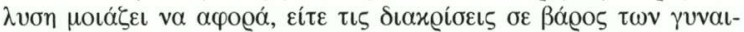

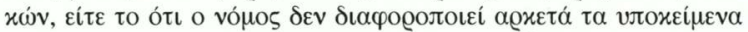

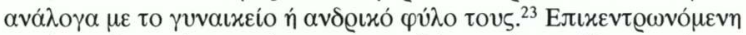

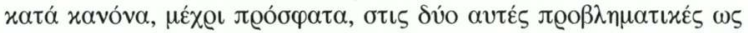

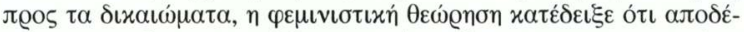

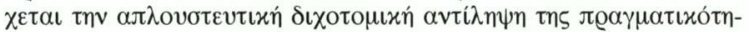

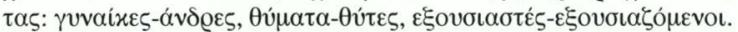

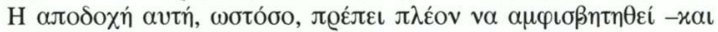

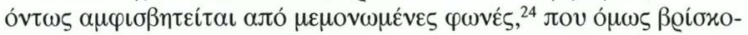

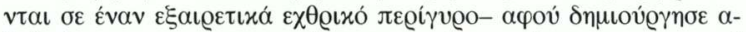

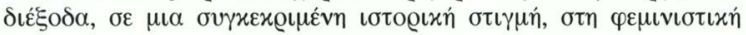

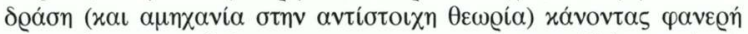

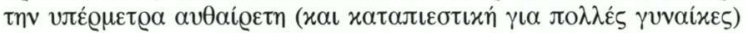

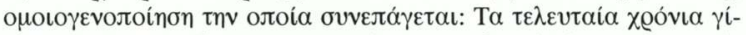

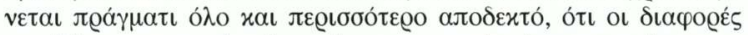

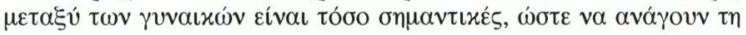

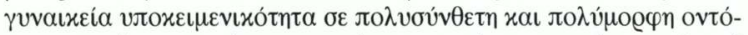

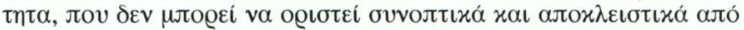

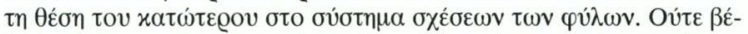

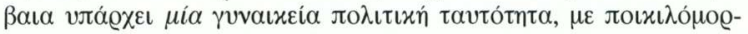

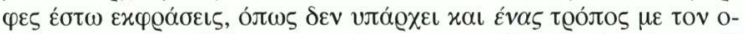

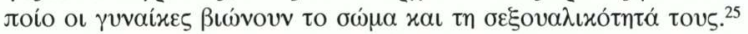

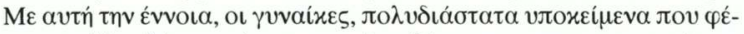

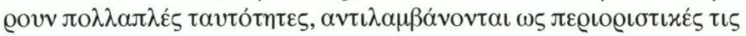

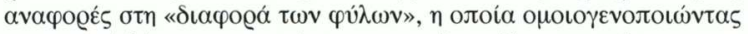

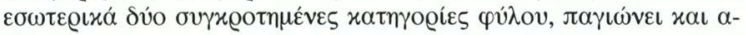

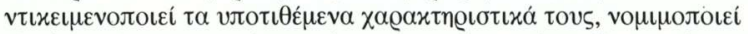

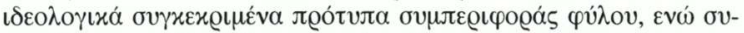

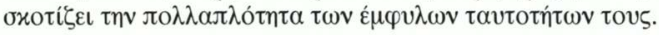

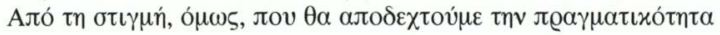

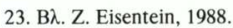

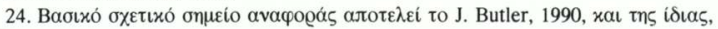
1993.

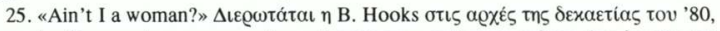

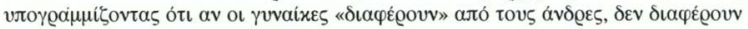

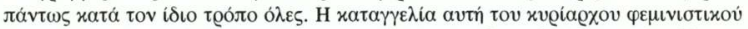

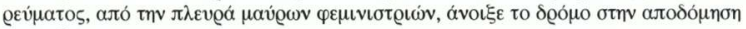

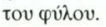




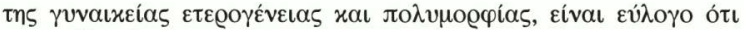

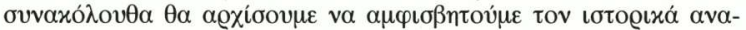

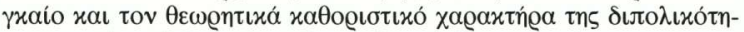

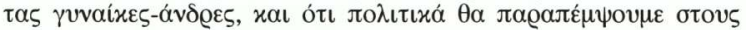

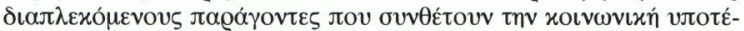

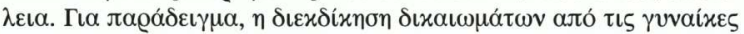

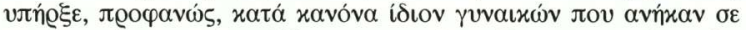

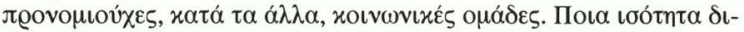

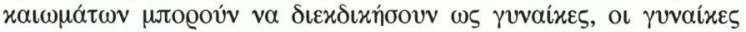

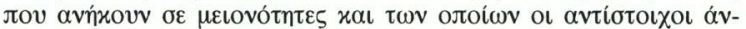

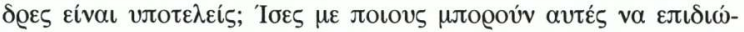

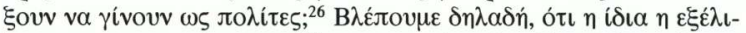

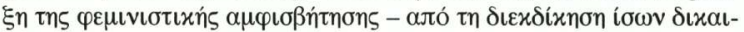

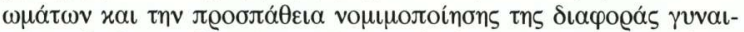

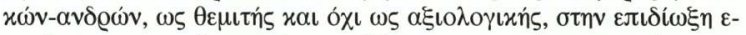

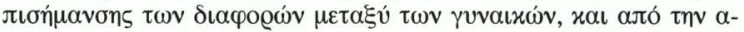

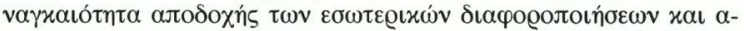

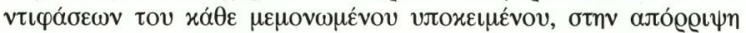

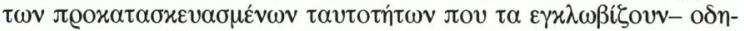

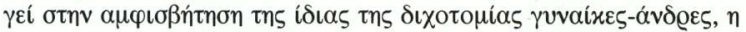

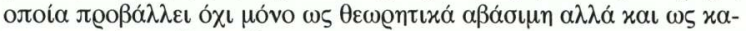
$\tau \alpha \pi \iota \varepsilon \sigma \tau \iota x \eta ́ ~ \gamma \iota \alpha$ ó

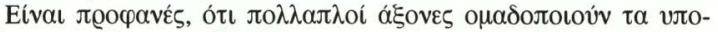

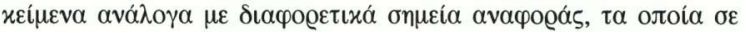

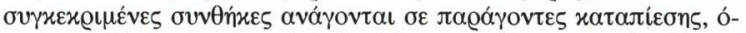

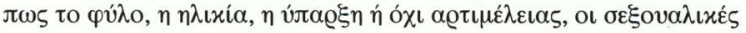

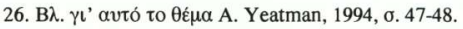

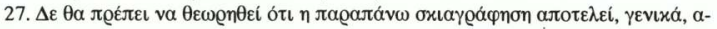

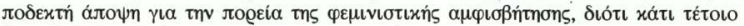

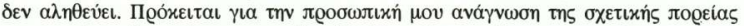

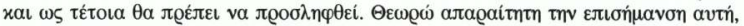

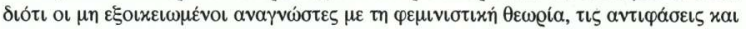

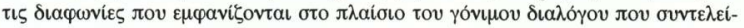

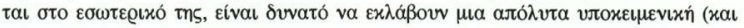

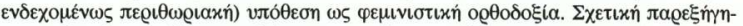

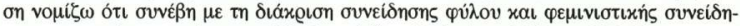

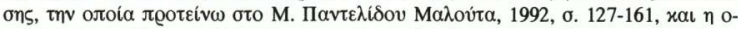

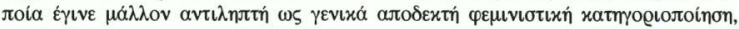

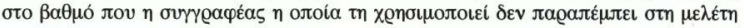

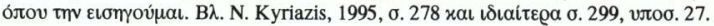




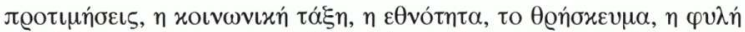

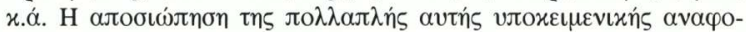

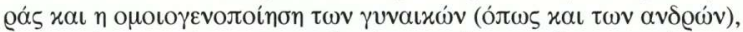

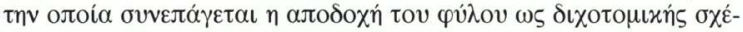

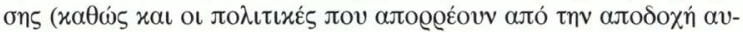

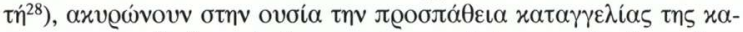

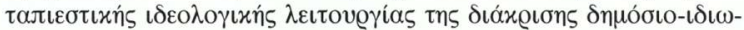

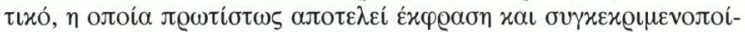

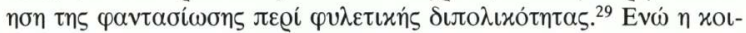

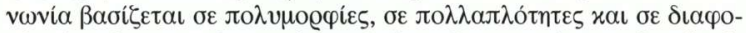

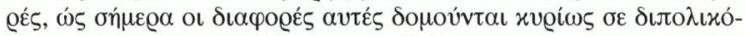

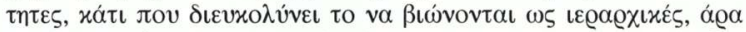

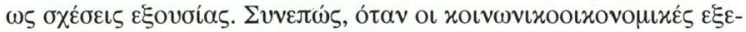

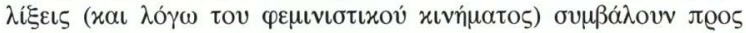

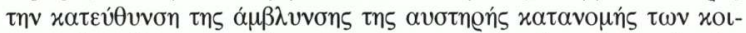

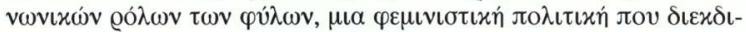

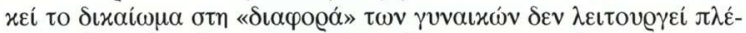

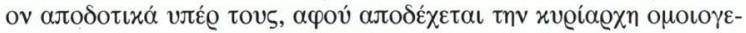

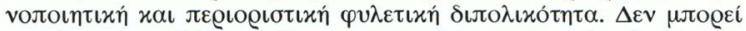

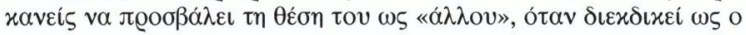

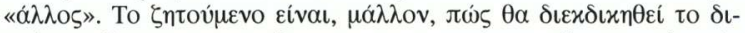

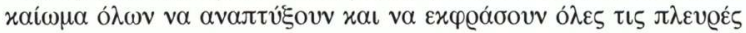

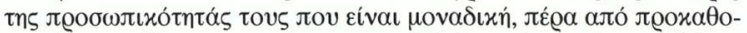

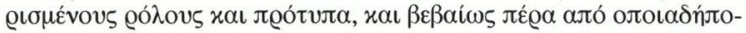

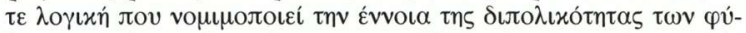

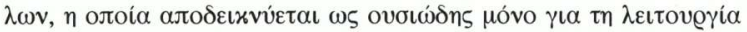

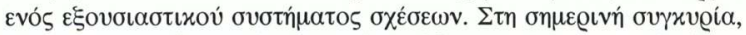

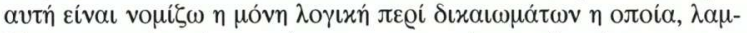

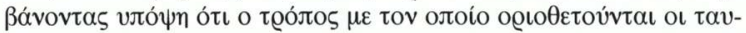

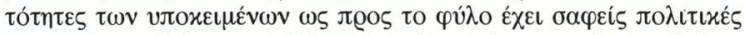

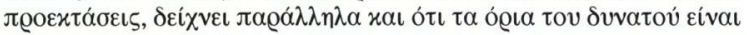

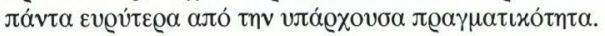

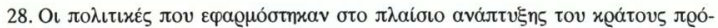

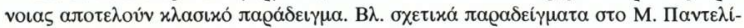

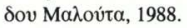

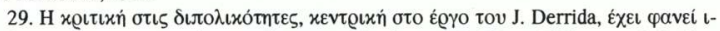

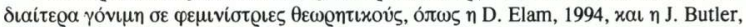

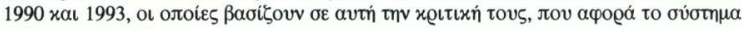

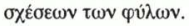




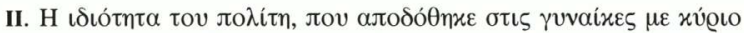

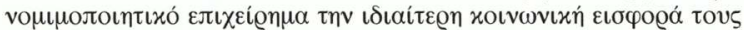

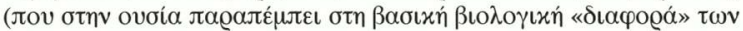

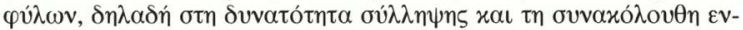

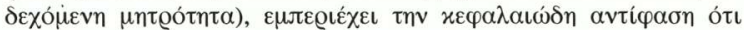

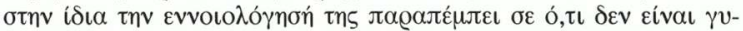

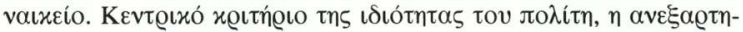

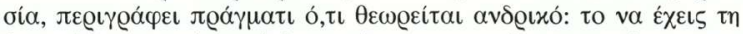

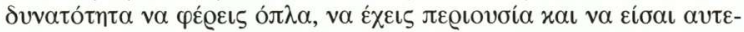

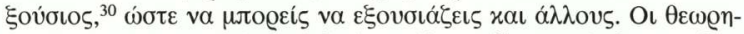

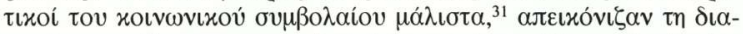

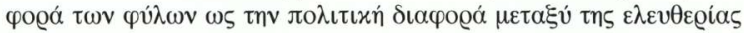

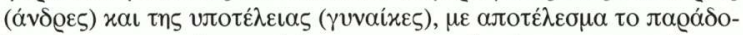

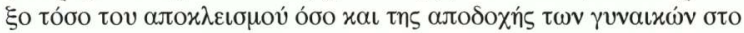

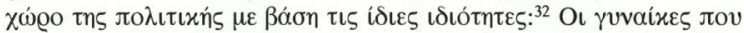

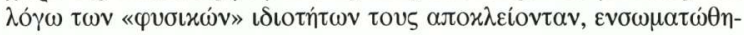

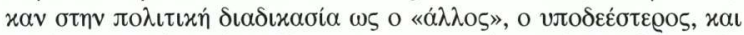

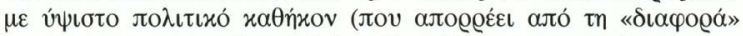

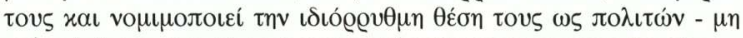

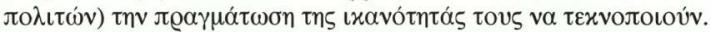

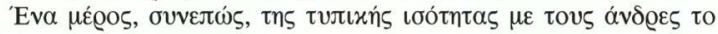

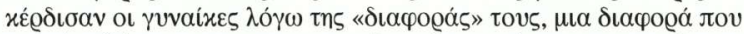

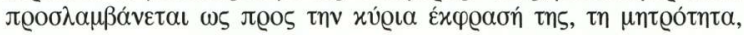

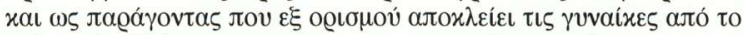

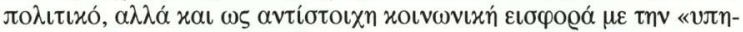

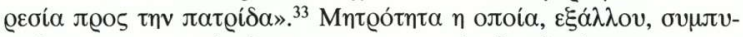

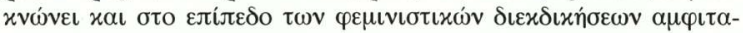

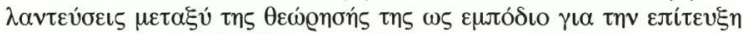

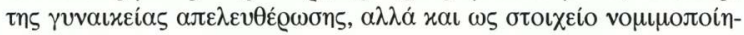
ońs тทร. ${ }^{34}$

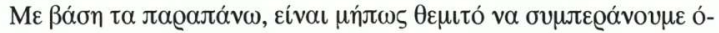

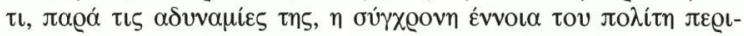

30. C. Pateman, 1989, б. 185 x.є.

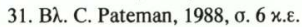

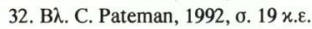

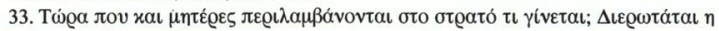

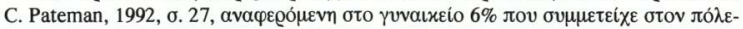

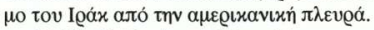

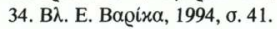




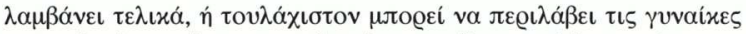

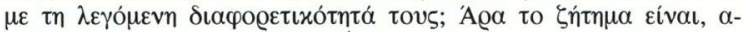

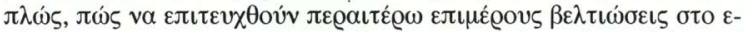

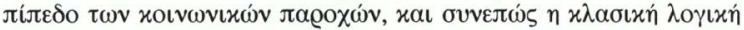

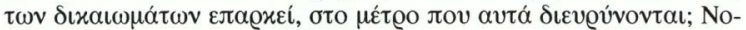

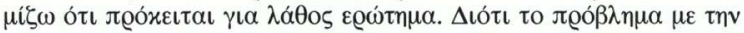

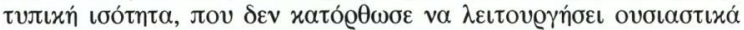

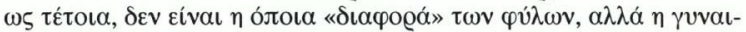

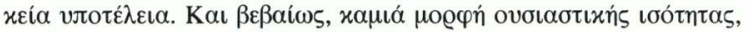

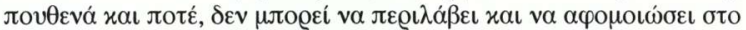

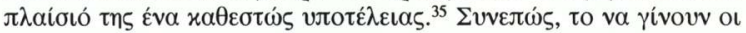

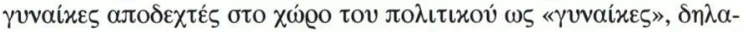

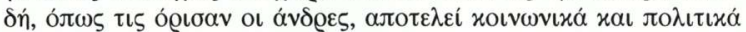

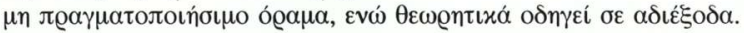

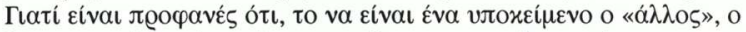

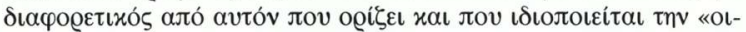

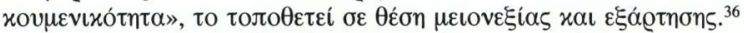

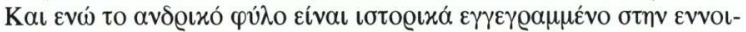

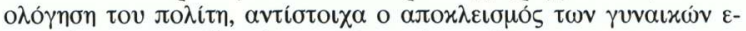

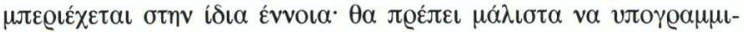

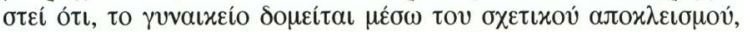

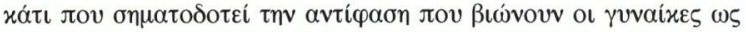

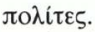

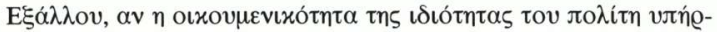

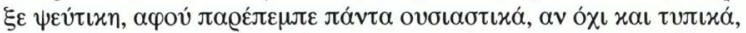

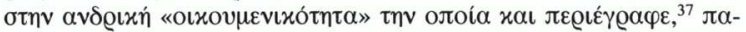

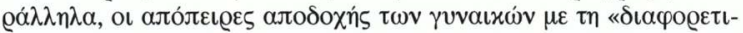

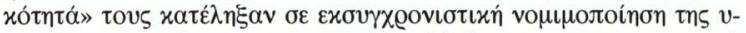

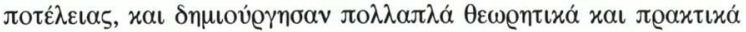

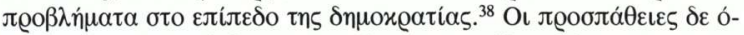

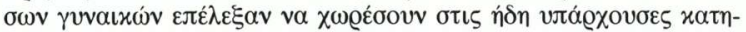

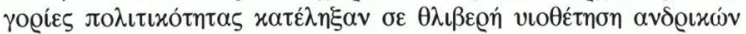

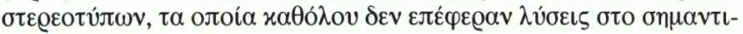

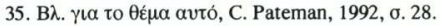

36. J. Flax, 1993, б. 139.

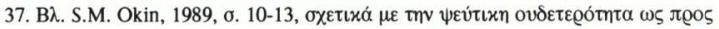
to $\varphi \dot{\lambda}$ o.

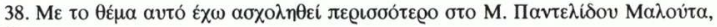
1996. 


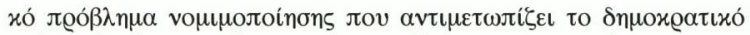

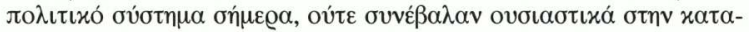

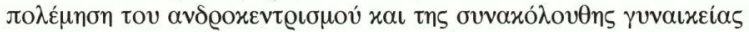

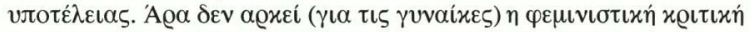

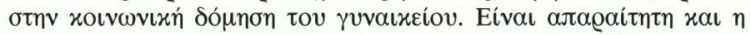

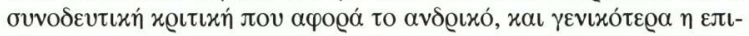

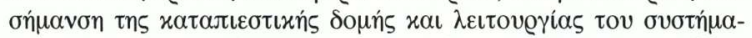

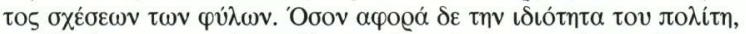

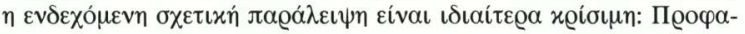

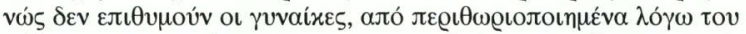

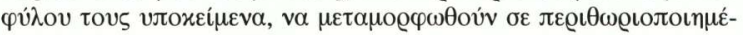

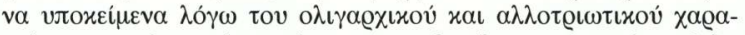

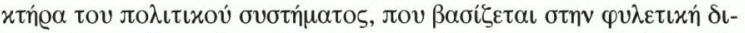

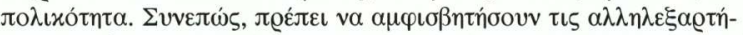

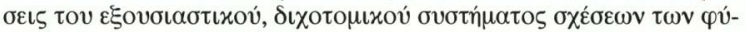

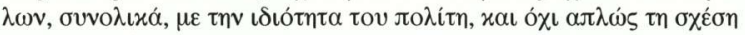

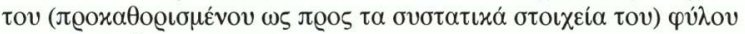

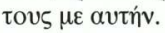

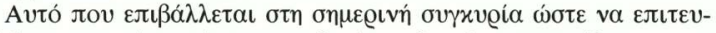

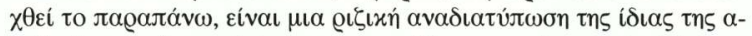

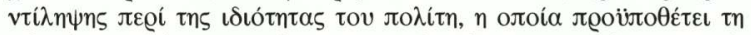

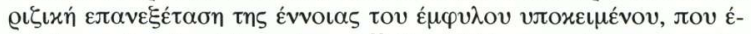

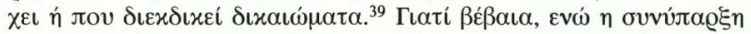

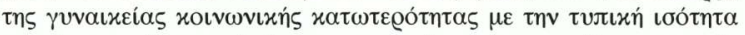

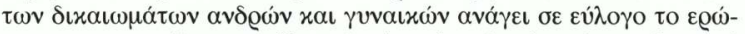

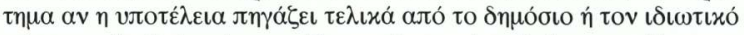

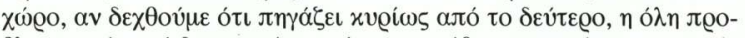

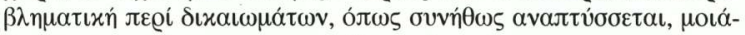

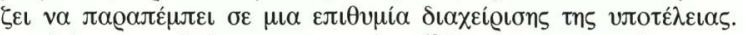

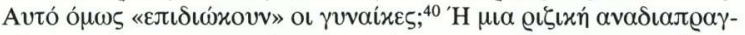

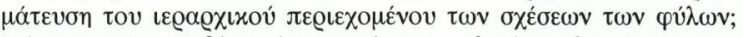

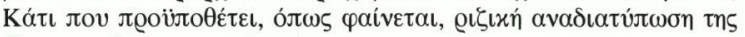

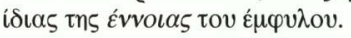

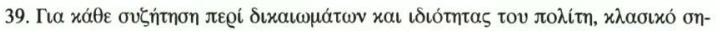

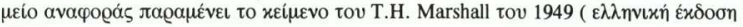
1995).

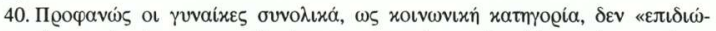

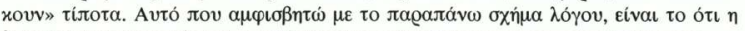

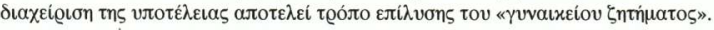




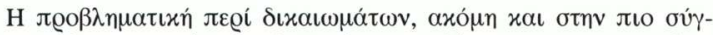

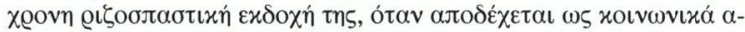

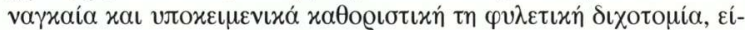

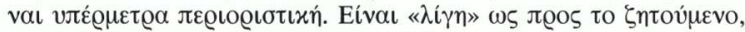

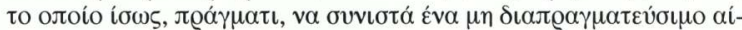

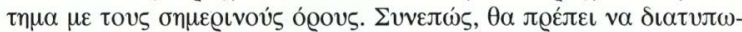

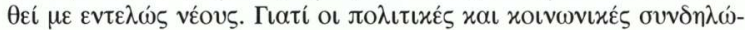

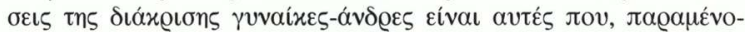

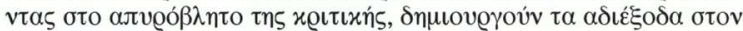

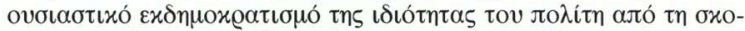

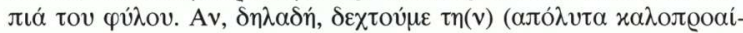

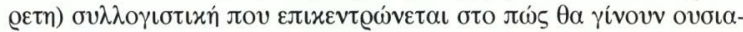

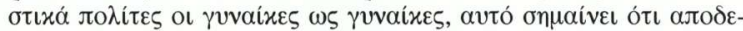

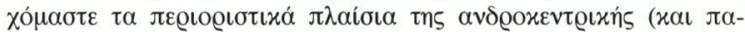

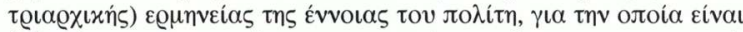

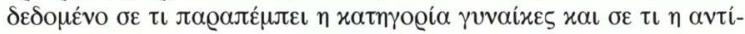

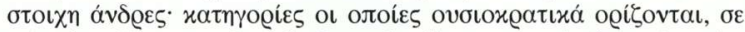

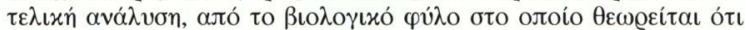

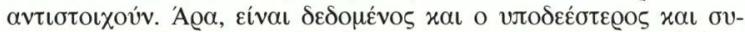

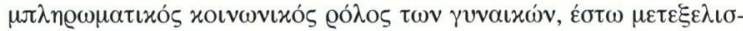

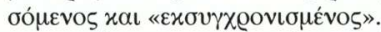

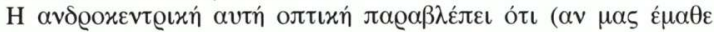

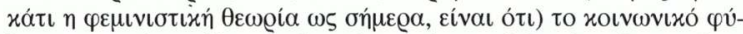

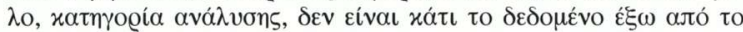

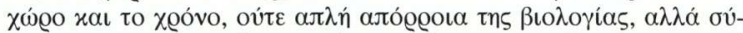

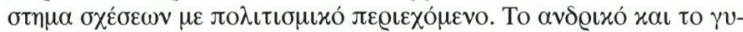

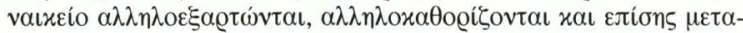

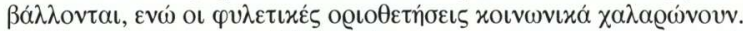

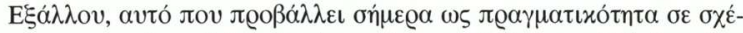

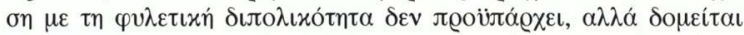

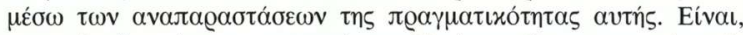

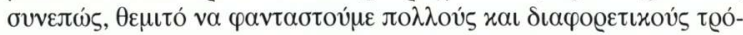

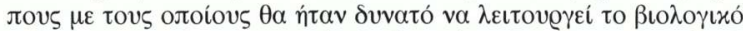

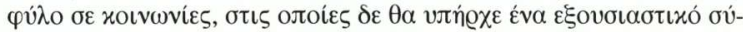

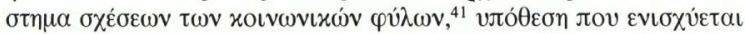

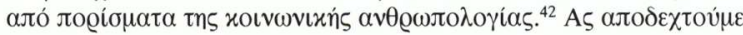

41. B $\lambda$. J. Flax, 1993, б. 140.

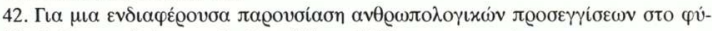

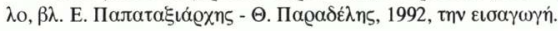




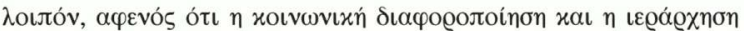

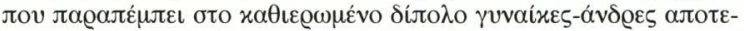

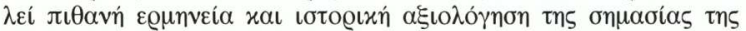

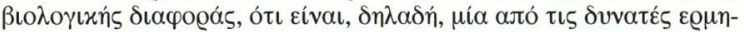

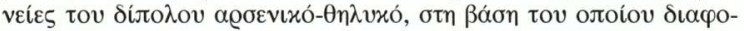

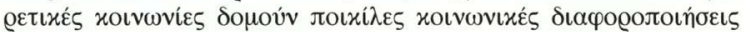

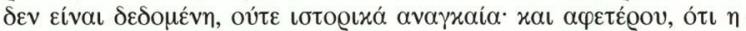

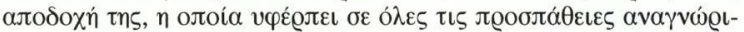

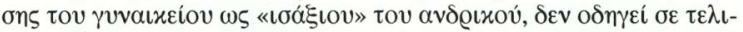

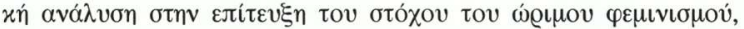

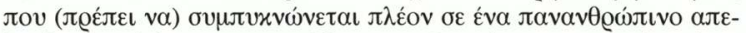

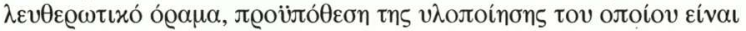

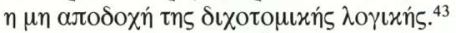

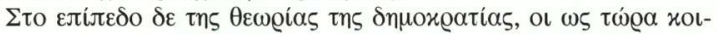

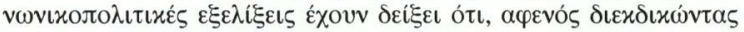

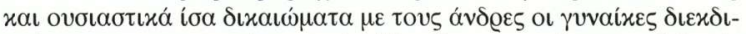

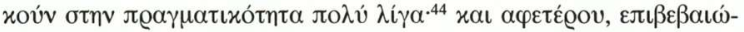

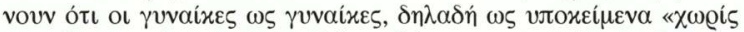

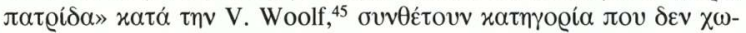

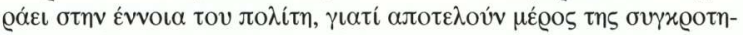

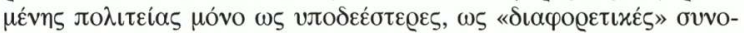

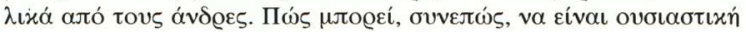

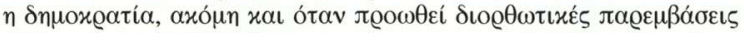

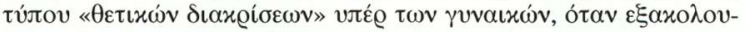

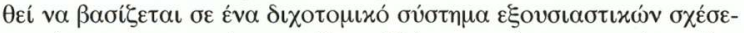

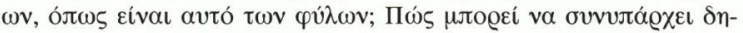

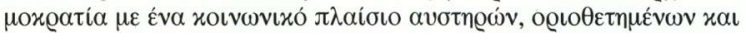

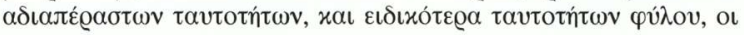

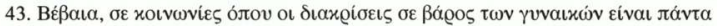

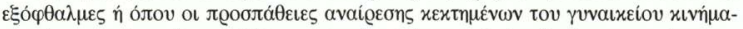

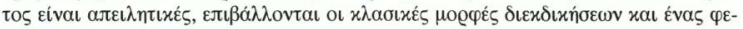

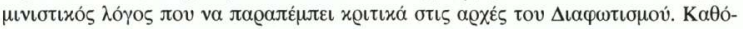

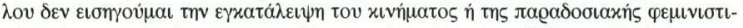

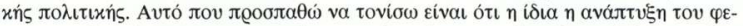

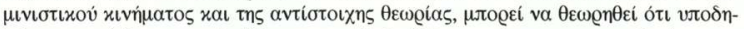

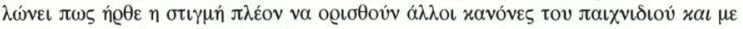

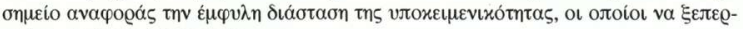

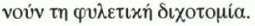

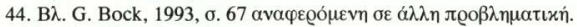

45. V. Woolf, 1938, б. 197. 


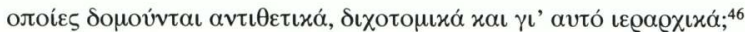

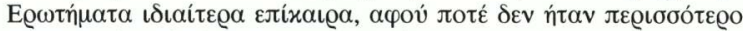

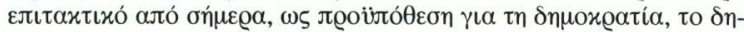

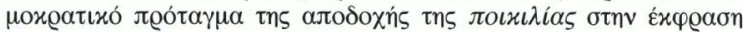

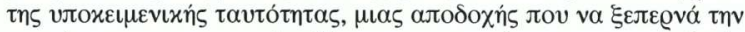

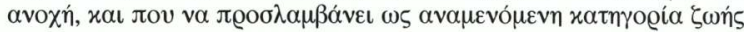

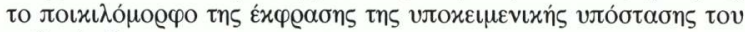

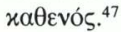

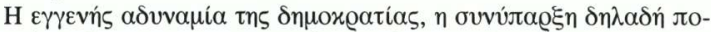

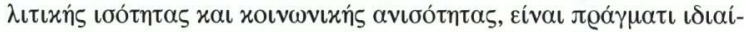

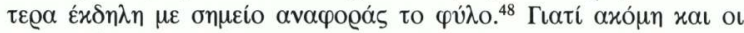

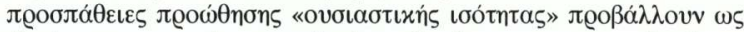

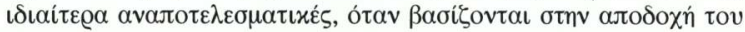

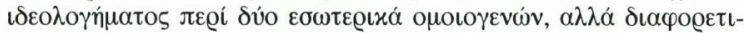

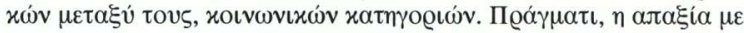

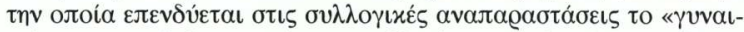

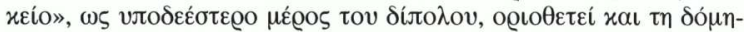

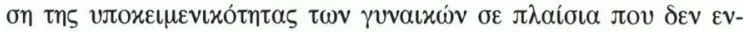

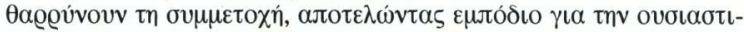

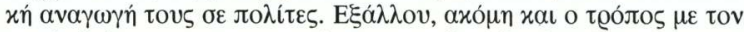

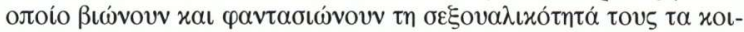

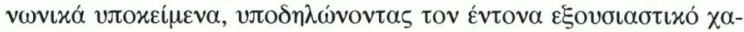

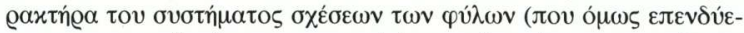

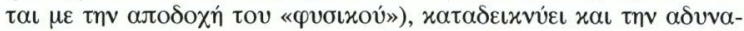

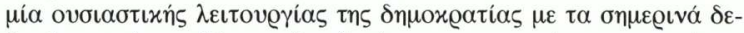

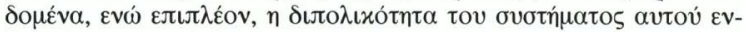

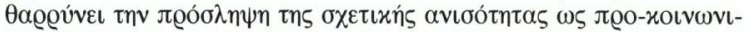

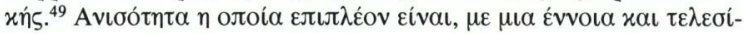

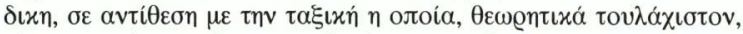

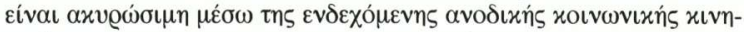

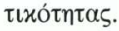

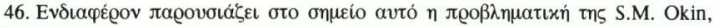

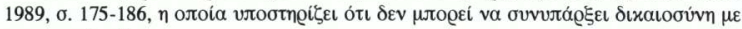

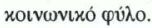

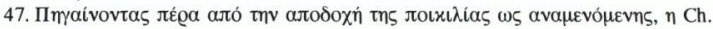

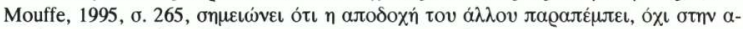

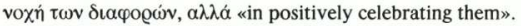

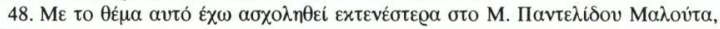
1996.

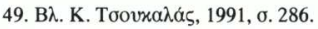




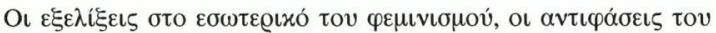

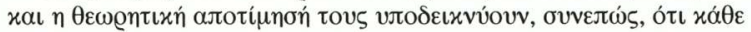

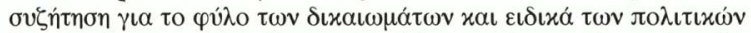

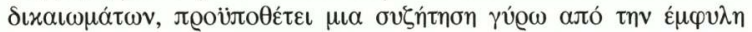

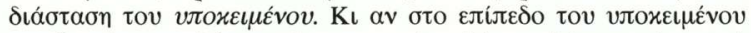

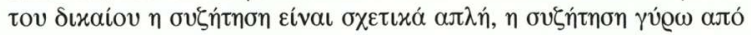

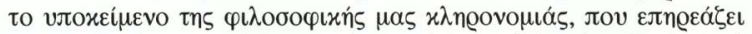

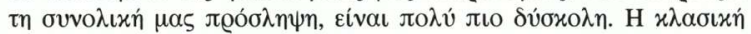

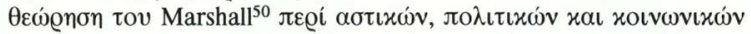

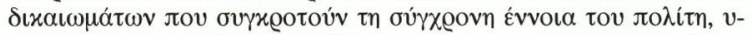

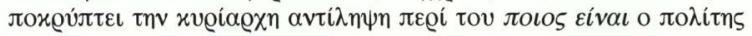

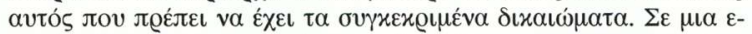

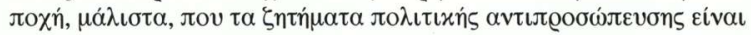

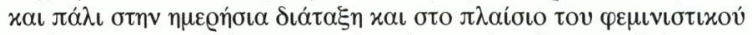

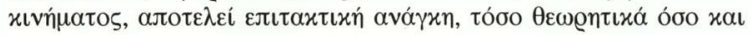

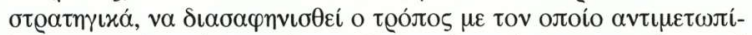

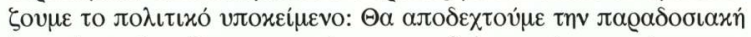

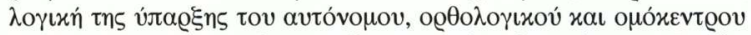

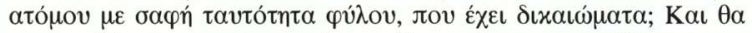

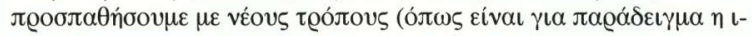

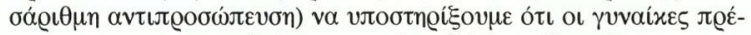

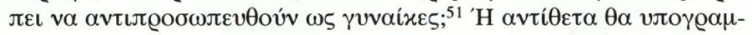

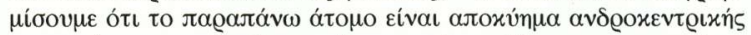

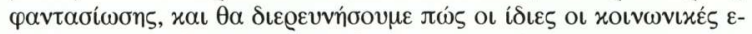

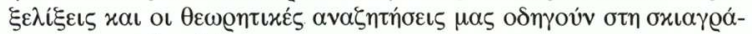

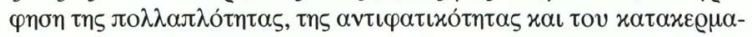

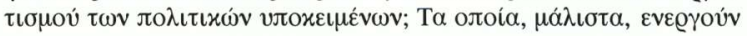

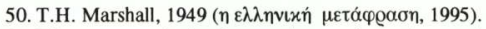

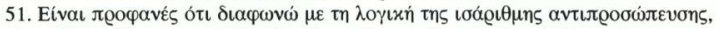

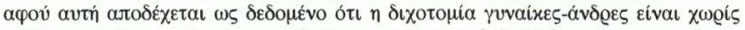

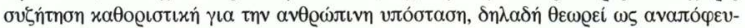

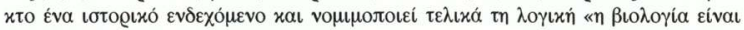

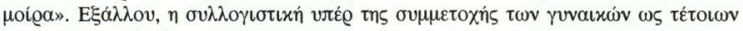

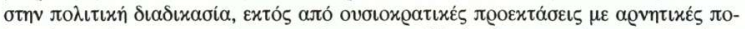

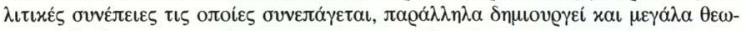

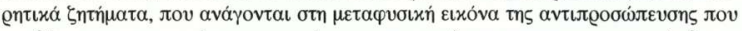

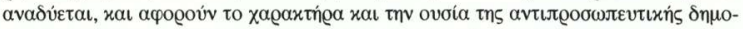

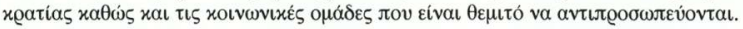

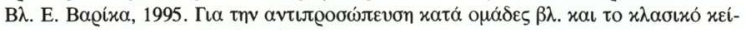

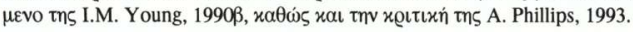




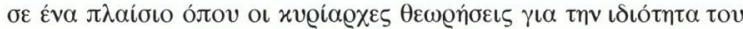

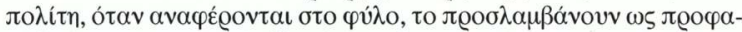

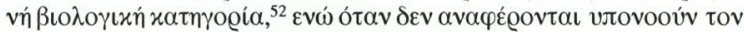

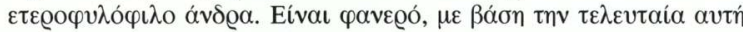

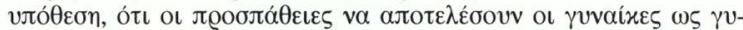

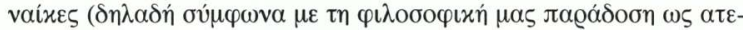

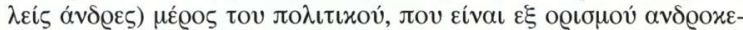

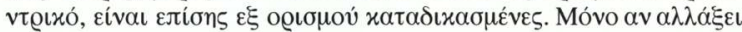

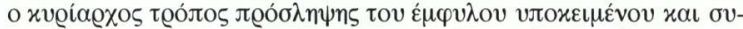

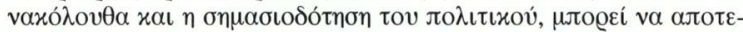

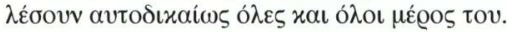

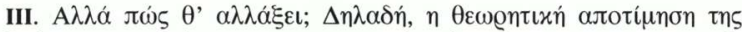

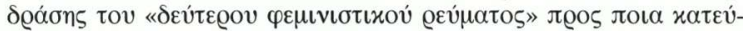

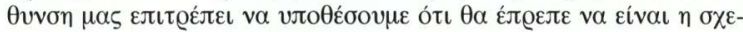

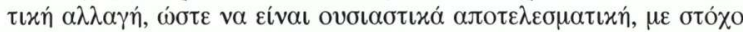

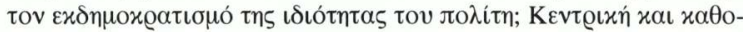

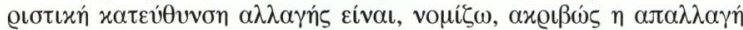

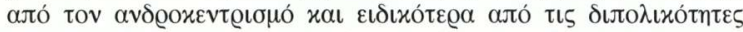

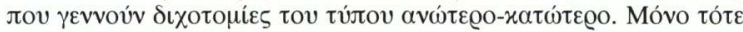

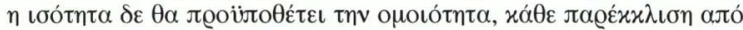

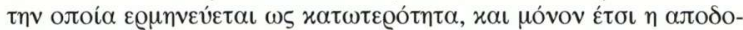

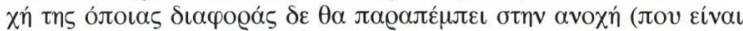

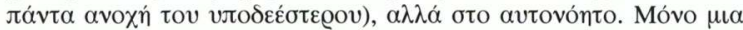

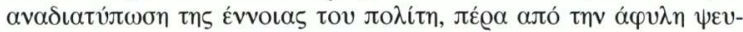

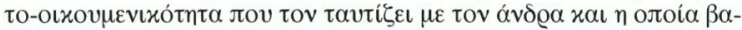

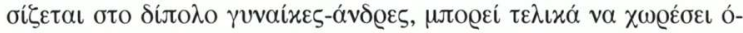

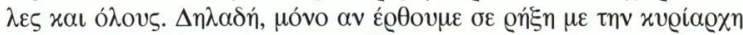

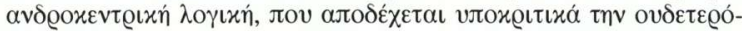

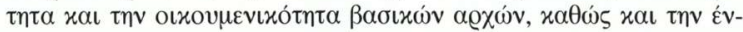

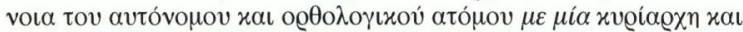

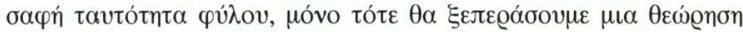

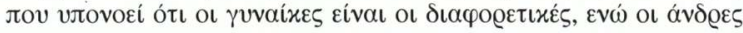

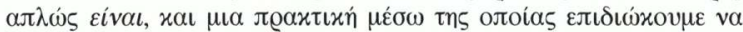

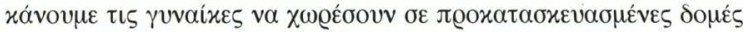

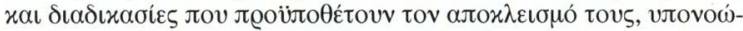

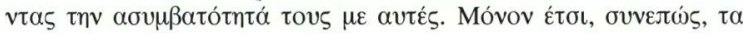

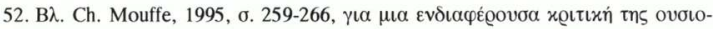

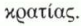




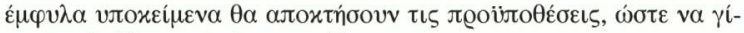

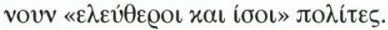

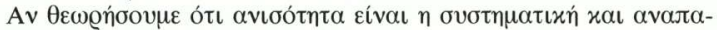

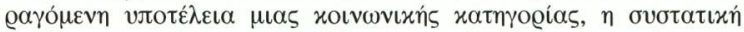

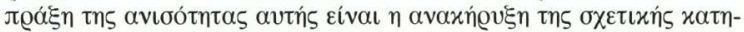

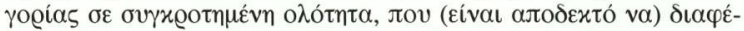

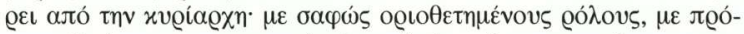

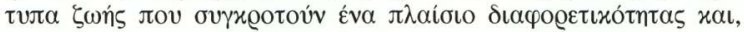

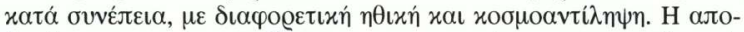

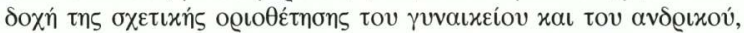

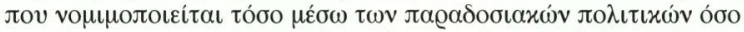

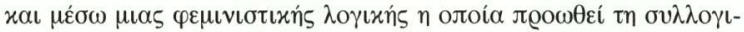

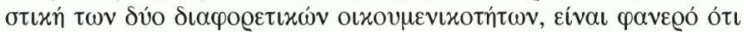

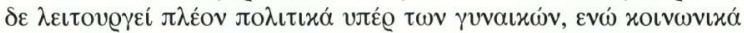

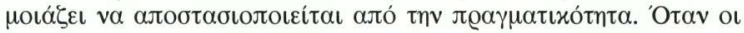

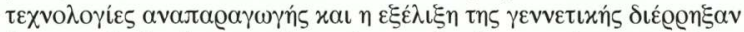

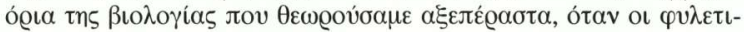

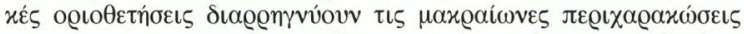

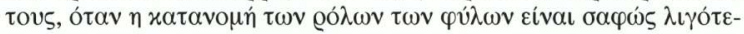

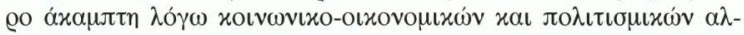

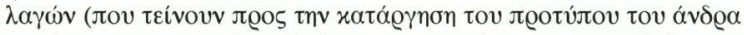

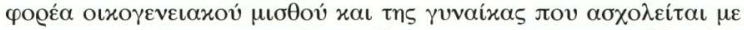

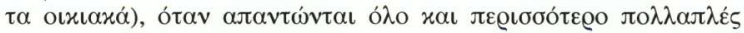

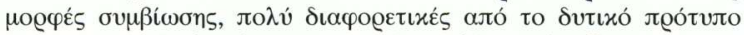

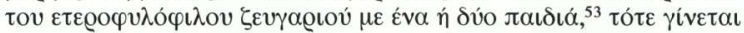

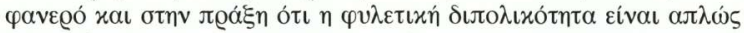

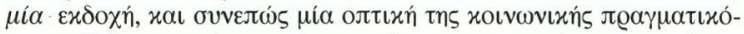

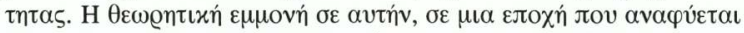

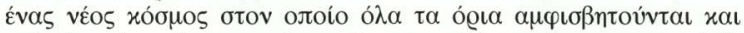

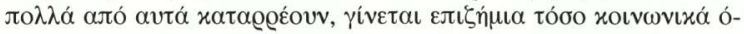

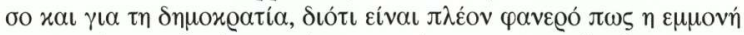

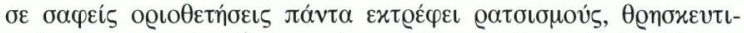

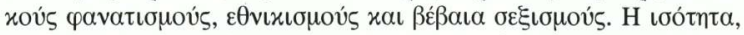

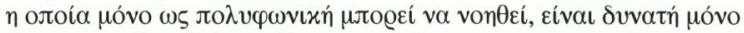

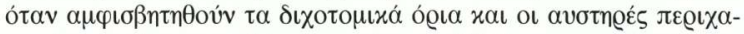

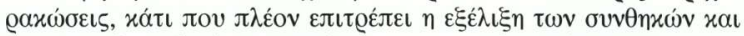

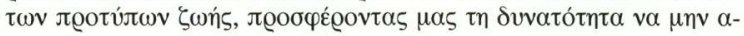

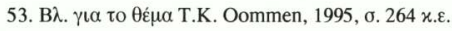




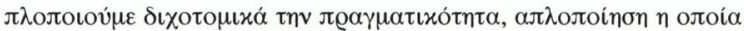

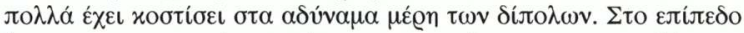

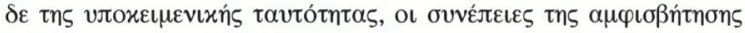

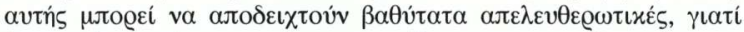

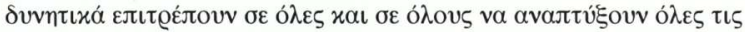

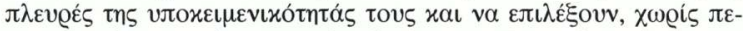

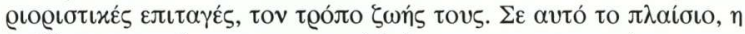

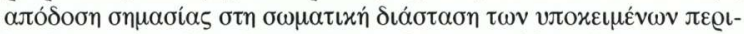

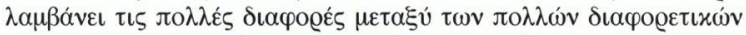

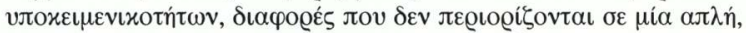

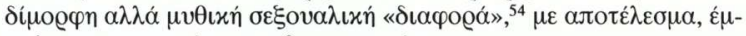

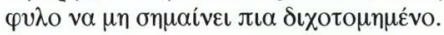

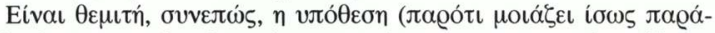

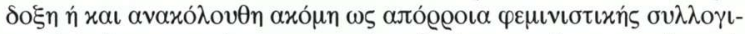

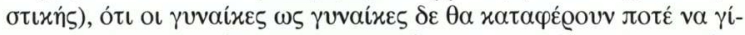

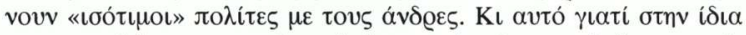

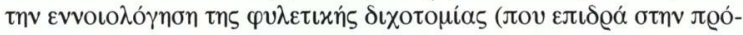

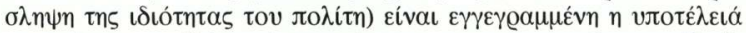

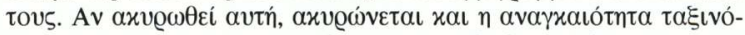

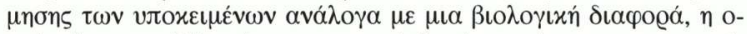

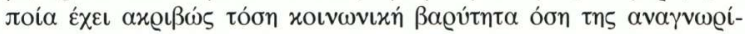

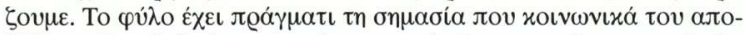

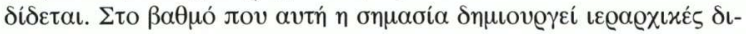

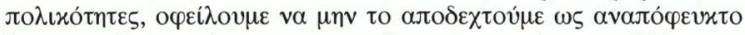

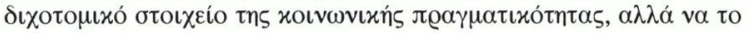

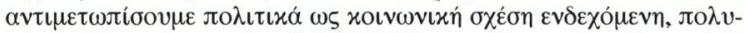

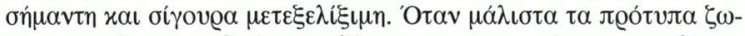

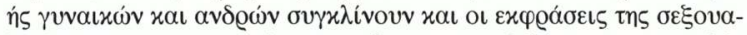

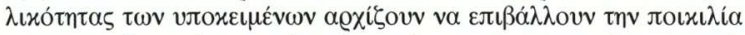

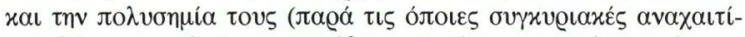

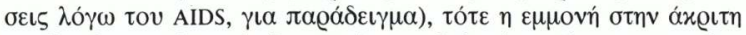

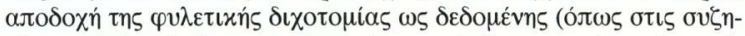

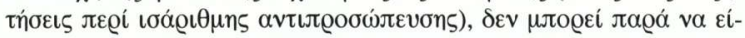

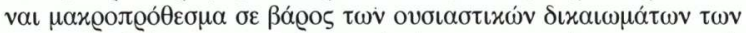

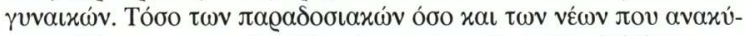

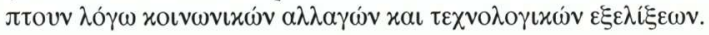

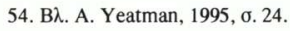




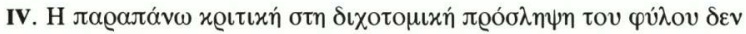

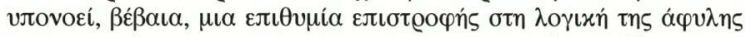

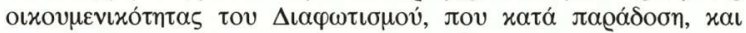

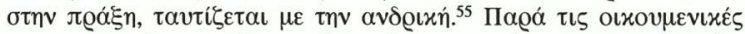

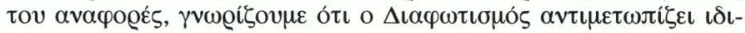

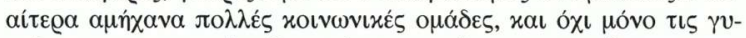

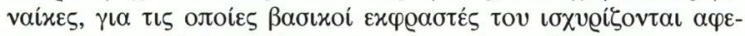

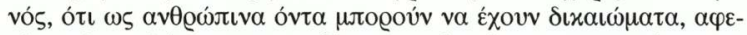

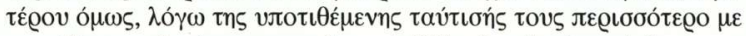

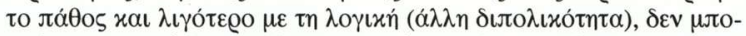

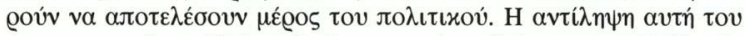

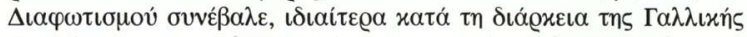

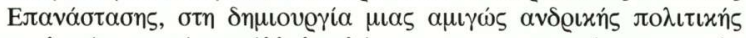

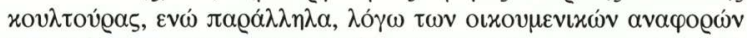

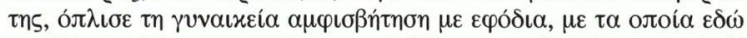

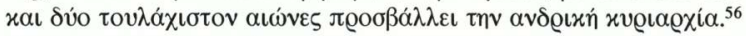

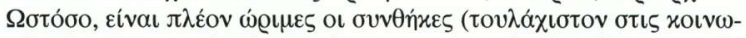

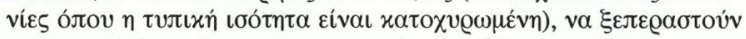

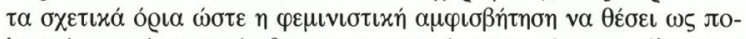

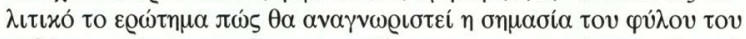

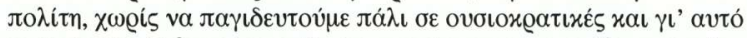

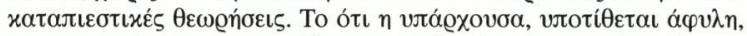

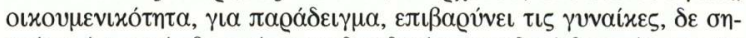

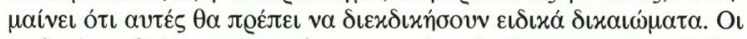

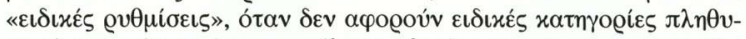

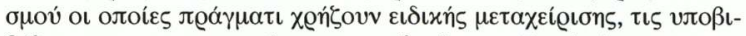

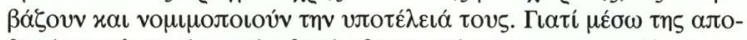

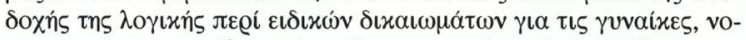

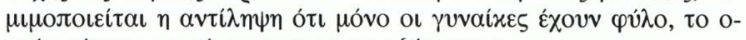

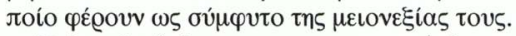

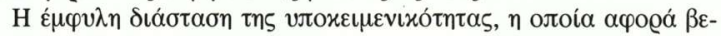

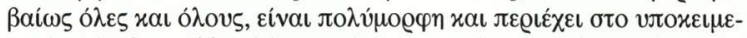

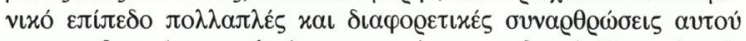

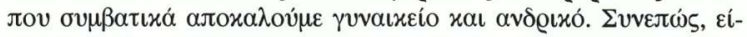

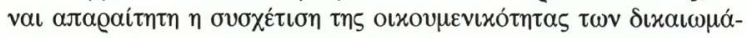

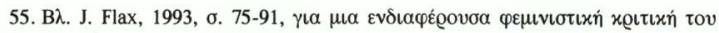
$\Delta \iota{ }^{\prime} \omega \tau \iota \sigma \mu o v ́$.

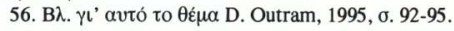




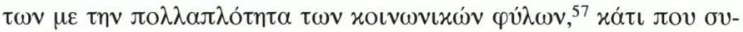

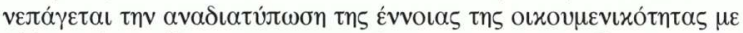

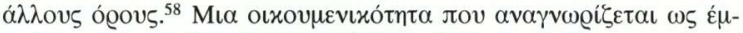

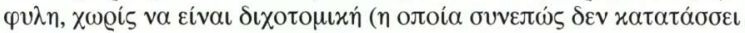

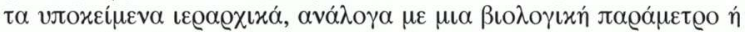

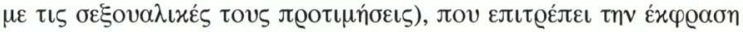

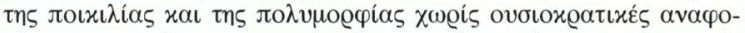

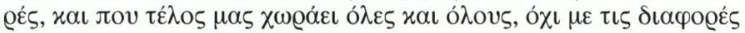

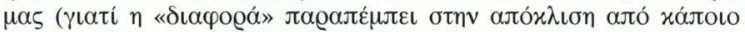

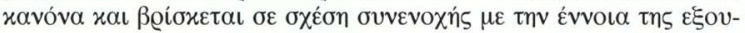

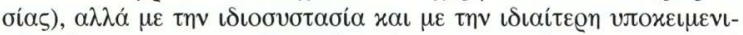

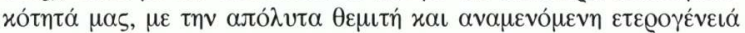
$\mu \alpha 5$.

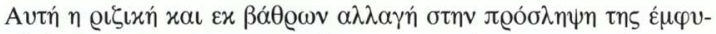

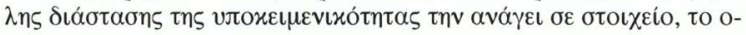

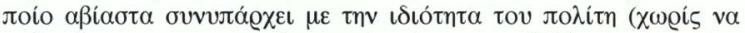

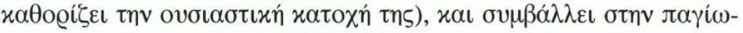

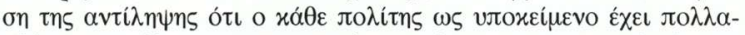

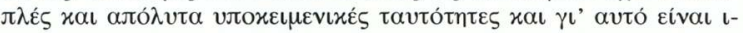

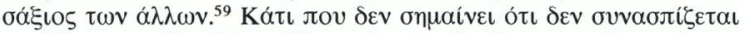

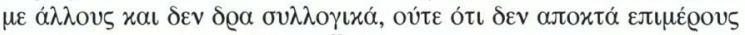

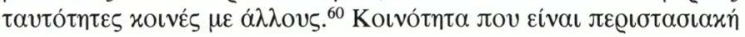

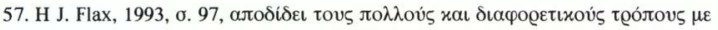

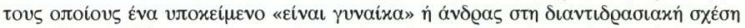

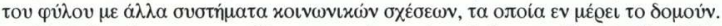

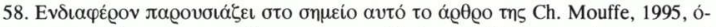

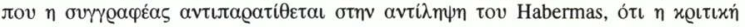

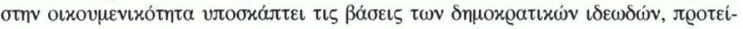

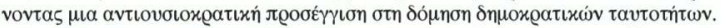

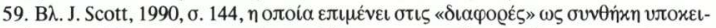

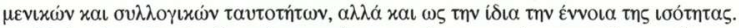

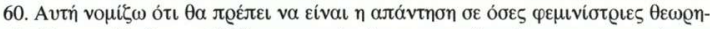

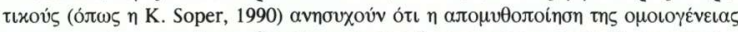

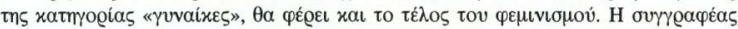

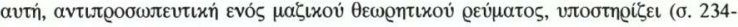

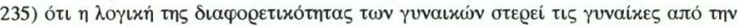

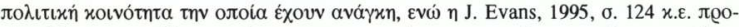

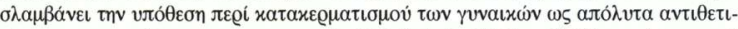

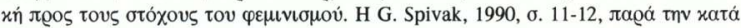

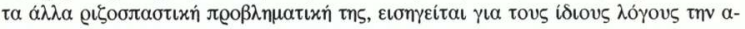

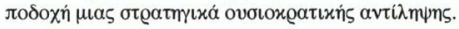




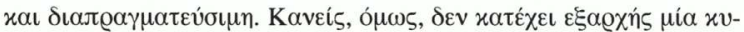

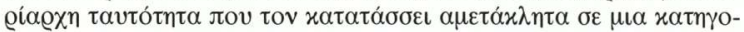

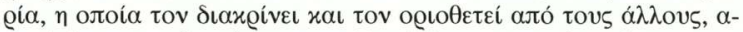

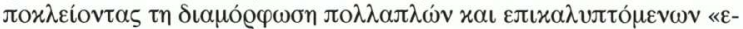

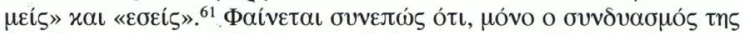

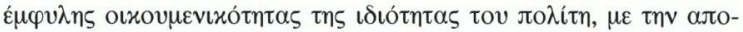

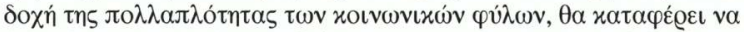

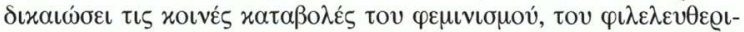

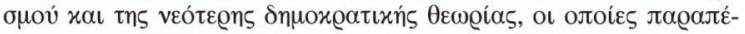

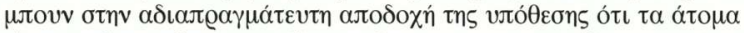

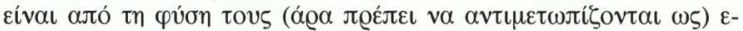

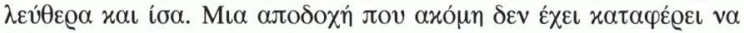

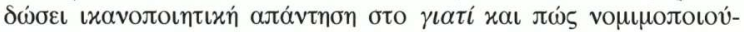

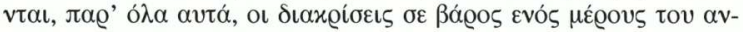

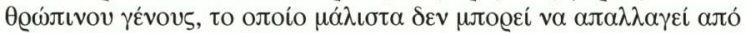

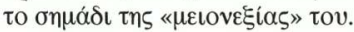

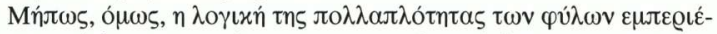

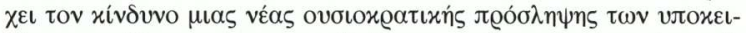

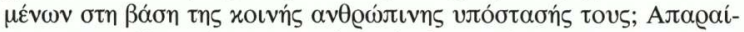

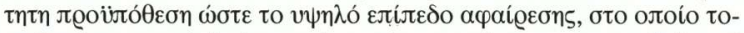

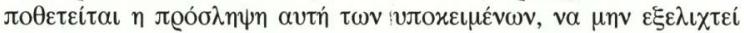

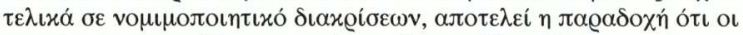

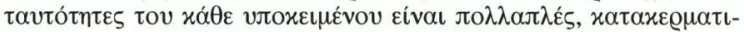

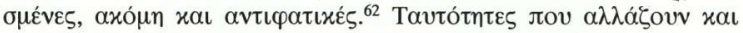

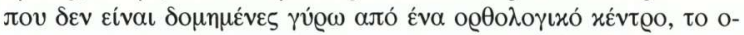

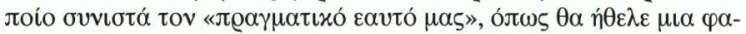

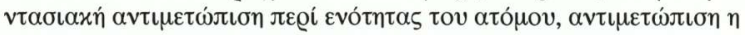

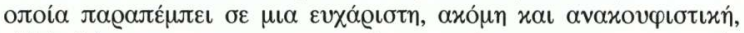

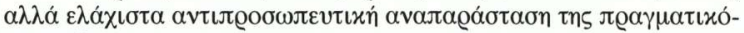
$\tau \eta \tau \alpha_{5} .{ }^{63}$

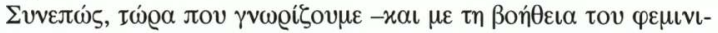

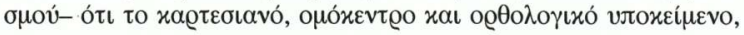

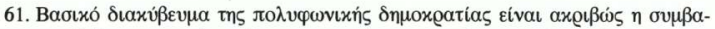

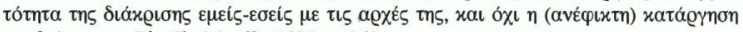

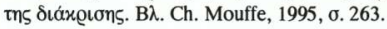

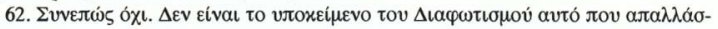

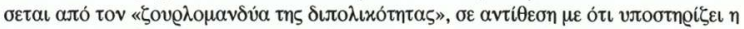

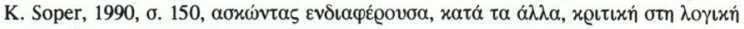
tnऽ aлoðó

63. B $\lambda$. S. Hall, 1990. 


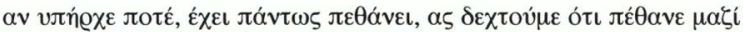

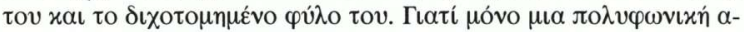

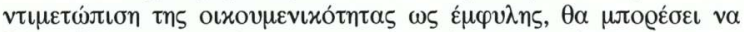

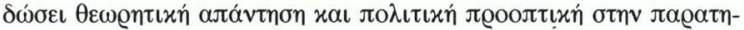

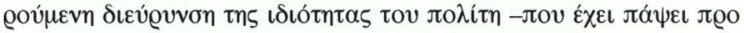

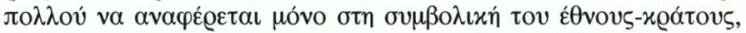

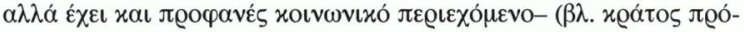

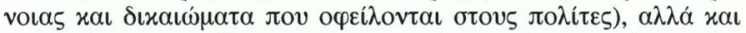

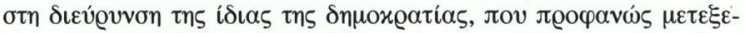

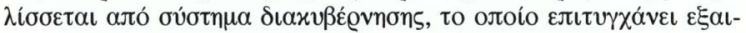

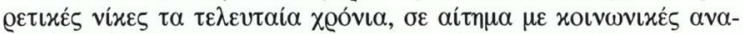

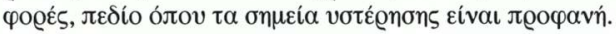

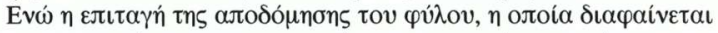

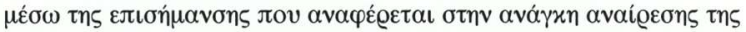

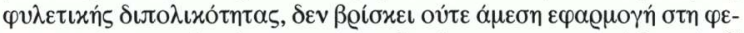

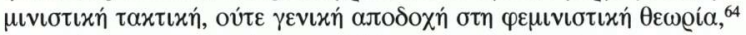

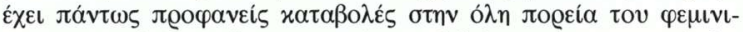

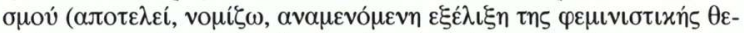

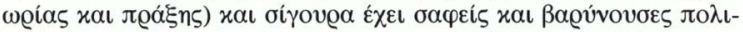

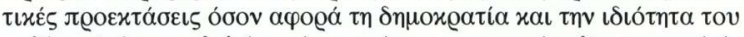

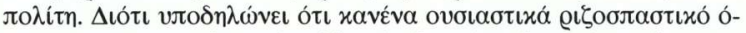

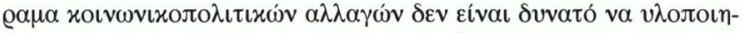

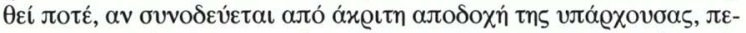

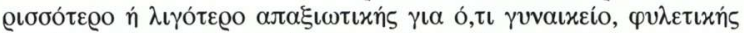

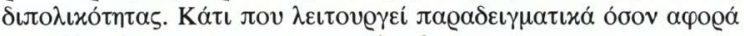

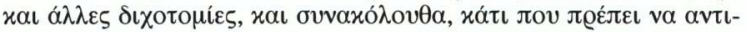

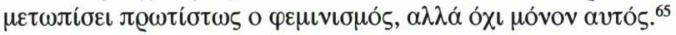

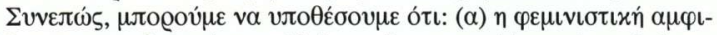

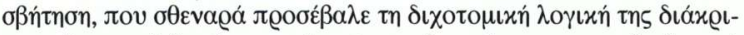

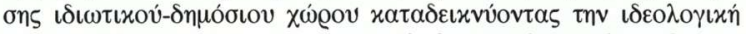

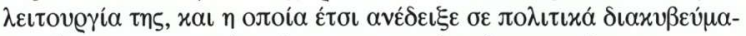

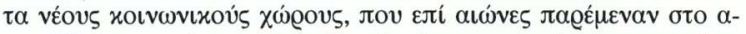

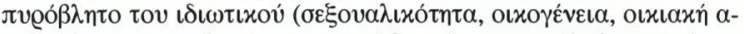

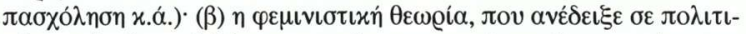

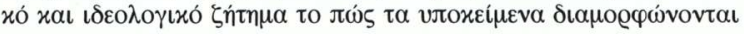

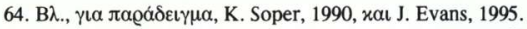

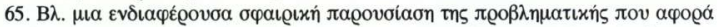

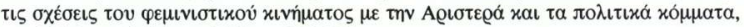

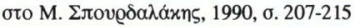




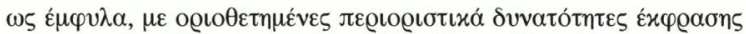

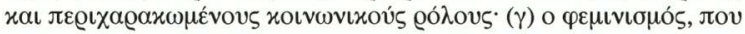

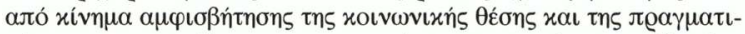

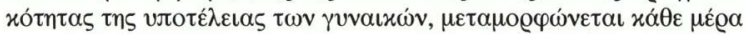

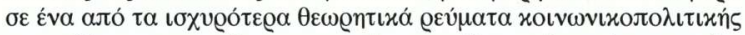

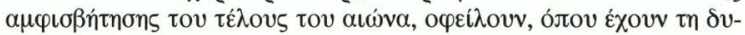

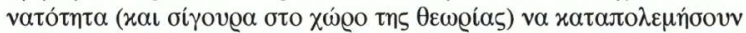

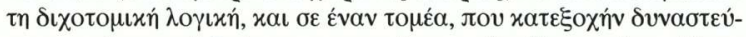

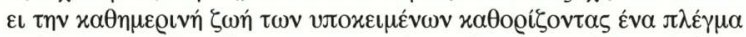

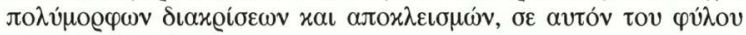

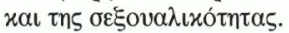

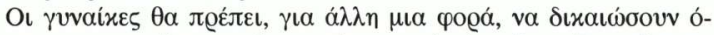

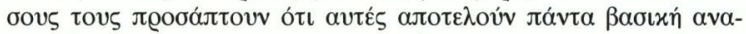

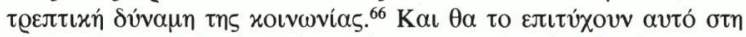

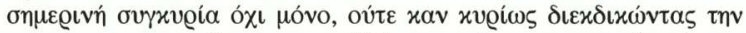

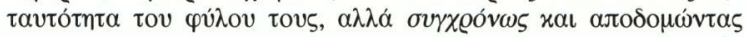
זๆv.

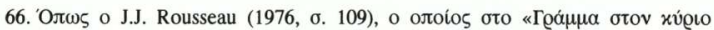

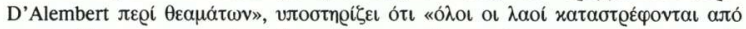

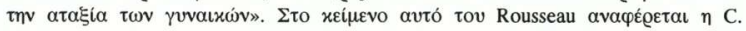
Pateman, 1989, б. 17. 


\section{BIBAIOГРАФIKEЕ ANAФOPE}

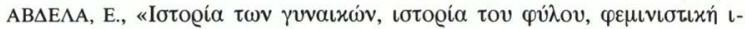

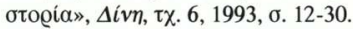

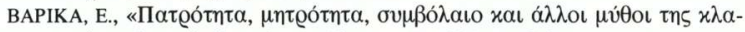

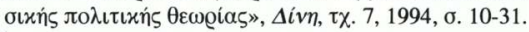

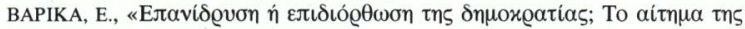

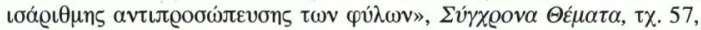
1995, б. 42-58.

Bethke, Elshtain J., Public man private woman, Princeton University Press, Princeton 1981.

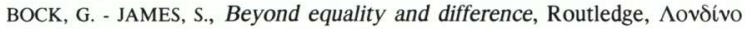
1992.

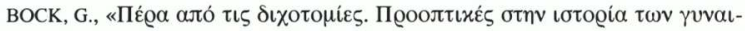

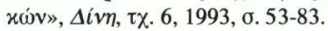

BUTLER, J., «Variations on sex and gender», oto S. Benhabib - D. Cornell ( $\varepsilon$ $\pi \iota \mu)$, Feminism as critique, Polity Press, Cambridge 1987.

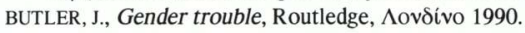

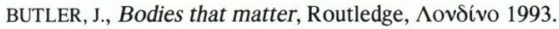

DALTON, R.J. - KUECHLER, M., Challenging the political order: New social and political movements in western democracies, Polity Press, Cambridge 1990 .

DIETZ, M., «Citizenship with a feminist face. The problem with maternal

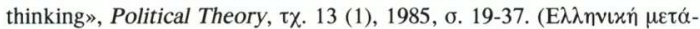

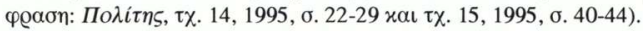

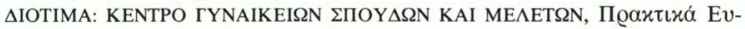

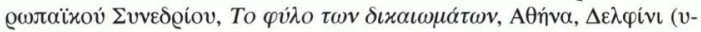

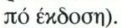

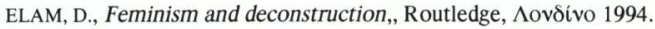

EISENTEIN, Z., The female body and the law, University of California Press, Berkeley 1988.

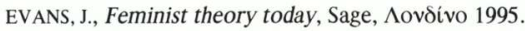

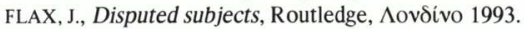

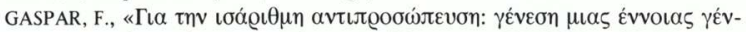

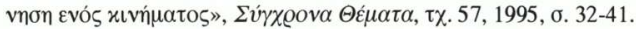

GORDON, L., Woman's body woman's right, Grossman, Néa Yó@xn 1976.

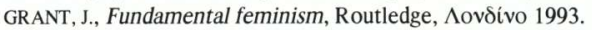

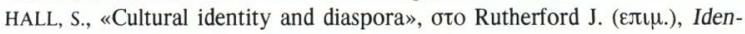

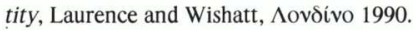

HOOKS, B., Ain't I a woman? Black women and feminism, South End Press, Bơtóvm 1981.

KYRIAZIS, N., «Feminism and the status of women in Greece», oto D. Con- 
stas- Th. Stavrou, Greece prepares for the 21st century, The Johns Hopkins University Press, Baltimore 1995.

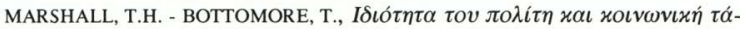
$\xi \eta$, Gutenberg, A $\theta \dot{\eta} v \alpha 1995$.

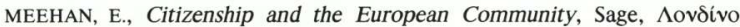
1993.

MOUFFE, CH., «Post-Marxism: Democracy and identity», Society and Space,

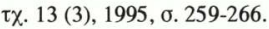

OKIN, S.M., Women in western political thought, Princeton University Press, Princeton 1979.

OKIN, S.M., Justice, gender and the family, Basic Books, Né $\alpha$ Yó@xn 1989.

OOMMEN, T.K., "Contested boundaries and emerging pluralism», International Sociology, $\tau \chi .3,1995$, o. 251-268.

OUTRAM, D.,The Enlightenment, Cambridge University Press, Cambridge 1995.

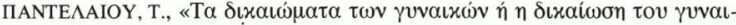

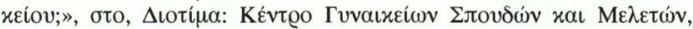

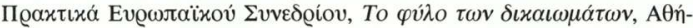
$v \alpha, \Delta \varepsilon \lambda \varphi i v \iota$ (vлó $\dot{x} x \delta \circ \sigma \eta)$.

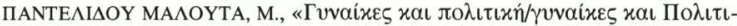

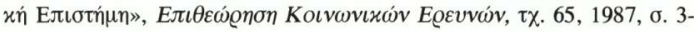
22.

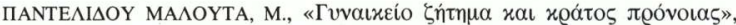

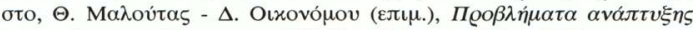

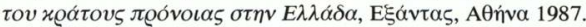

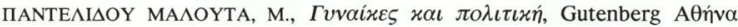
1992.

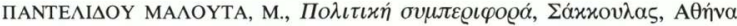
1993.

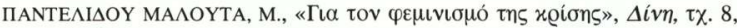
$1995 / 96$.

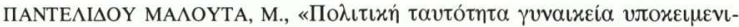

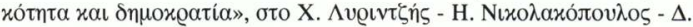

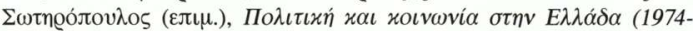

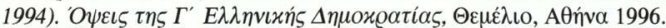

ПАПАТАЕІAPXH

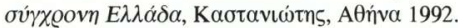

Pateman, C., The sexual contract, Polity Press, Cambridge 1988.

PATEMAN, C., The disorder of women, Polity Press, Cambridge 1989.

PATEMAN, C., «Equality, difference, subordination: the politics of motherhood and women's citizenship», oтo, G. Bock - S. James, Beyond equa-

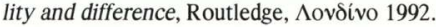


PHILlIPS, A., Democracy and difference, Polity Press, Cambridge 1993.

PHILlIPS, A., «Dealing with difference», Constellations, $\tau \chi .1$ (1), 1994, $\sigma$. 74-91.

RICH, A., Of woman born, Norton, Né $\alpha$ Yógxn 1976.

Rousseau, J.J., Politics and the arts, Cornell University Press, Né $\alpha$ Yó@ 1973.

RUDDICK, S., «Maternal thinking», Feminist Studies, $\tau \chi .6$ (2), 1980, б. 342367.

SCOTT, J., «Deconstructing equality-versus-difference», oto M. Hirsch - E.

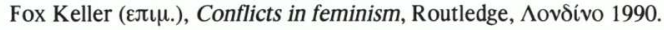

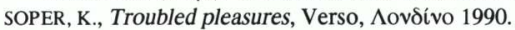

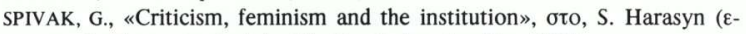

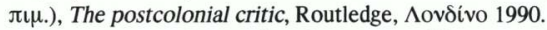

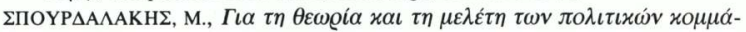

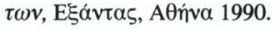

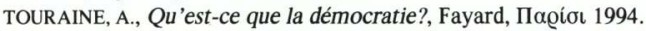

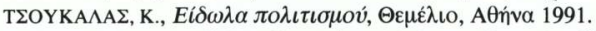

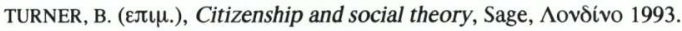

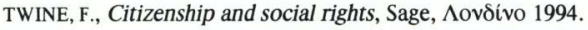

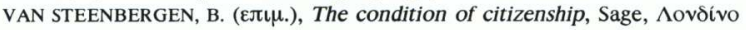
1994.

VARIKAS, E., «Refonder ou racommoder la démocratie?», French Politics and Society, $\tau \chi .12$ (4), 1994, o. 1-34.

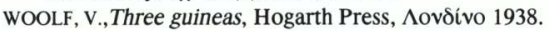

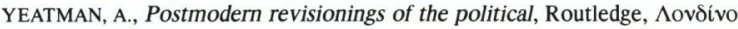
1994.

YOUNG, I.M., Throwing like a girl, Indiana University Press, Indianapolis 1990.

YOUNG, I.M., «Polity and group difference», $\sigma \tau$, C. Sunstein, Feminism and political theory, University of Chicago Press, ¿ıxáro 1990ß. 